\title{
FINITE-ELEMENT SURFACE-WATER MODELING SYSTEM: TWO-DIMENSIONAL FLOW IN THE HORIZONTAL PLANE- ADDENDUM TO THE USERS MANUAL
}

By Jonathan K. Lee

U.S. GEOLOGICAL SURVEY

Open-File Report 97-410

Prepared in cooperation with the

SOUTH FLORIDA WATER MANAGEMENT DISTRICT

Reston, Virginia 


\title{
U.S. DEPARTMENT OF THE INTERIOR
} BRUCE BABBITT, Secretary

\author{
U.S. GEOLOGICAL SURVEY \\ Charles G. Groat, Director
}

For additional information write to:

U.S. Geological Survey Branch of Regional Research Mail Stop 430 Reston, Virginia 20192
Copies of this report may be purchased from:

U.S. Geological Survey Branch of Information Services Box 25286 Denver, Colorado 80225-0286 


\section{CONTENTS}

Page

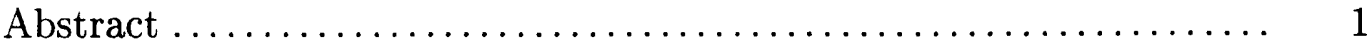

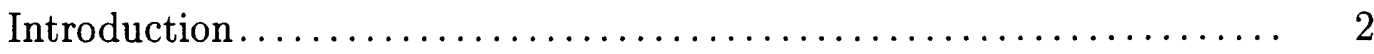

Addendum to section 4 . Governing equations ................... 3

Depth-averaged flow equations $\ldots \ldots \ldots \ldots \ldots \ldots \ldots \ldots \ldots \ldots, 3$

Bed shear stress.................................. 3

Surface shear stress ............................. 4

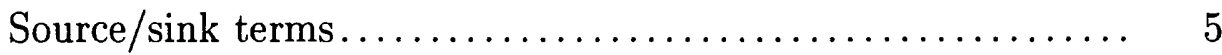

Ground-water inflow/outflow........................ 5

Flow through and under levees ......................... 7

Addendum to section 5. Finite-element equations................ 13

Residual expressions................................ 13

Derivative expressions .............................. 13

Application of boundary and special conditions-total

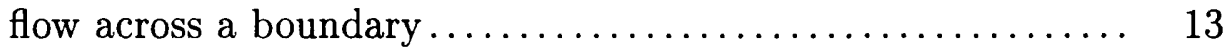

Addendum to section 6 . Modeling system operation .............. 15

Data collection ................................... 15

Network design $\ldots \ldots \ldots \ldots \ldots \ldots \ldots \ldots \ldots \ldots \ldots \ldots \ldots \ldots \ldots \ldots \ldots, 16$

General network layout ............................ 16

One-dimensional levees............................ 16

Addendum to section 8. Input data description ................. 18

Depth-averaged flow module: FLOMOD .................. 18

Program-control data set......................... 20

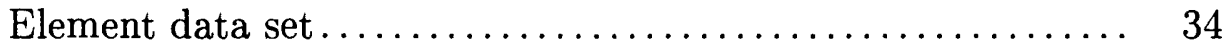

Node data set............................... 37

Turbulence-model data set $\ldots \ldots \ldots \ldots \ldots \ldots \ldots \ldots \ldots \ldots . \ldots \ldots$

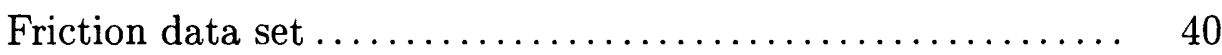

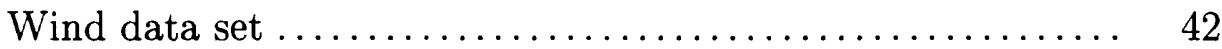

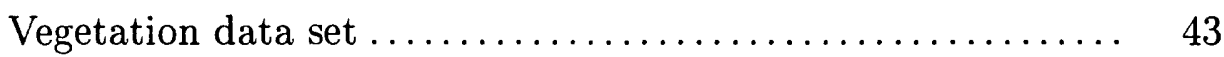

Precipitation data set............................ 44

Evapotranspiration data set........................ 45

Ground-water-seepage data set...................... 46

Ground-water-head data set........................ 47

Initial-condition data set $\ldots \ldots \ldots \ldots \ldots \ldots \ldots \ldots \ldots \ldots, 48$ 


\section{CONTENTS (Continued)}

Page

Boundary-condition data set $\ldots \ldots \ldots \ldots \ldots \ldots \ldots \ldots \ldots, 50$

Total-flow-cross-section data set.................... 54

Water-surface-elevation-cross-section data set............ 56

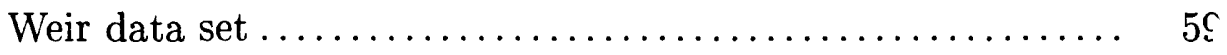

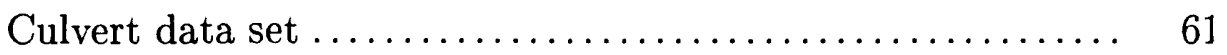

Levee data set $\ldots \ldots \ldots \ldots \ldots \ldots \ldots \ldots \ldots \ldots \ldots \ldots \ldots \ldots \ldots \ldots \ldots \ldots \ldots$

Flux-line data set............................... 65

Time-dependent data set......................... 66

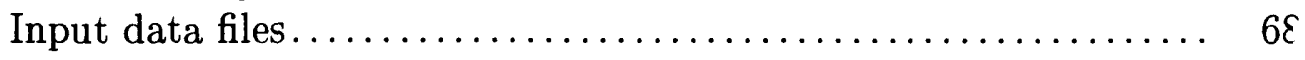

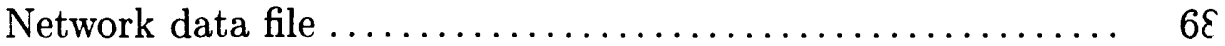

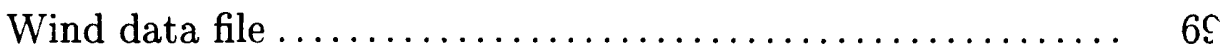

Ground-water-head data file........................ $7 \mathrm{C}$

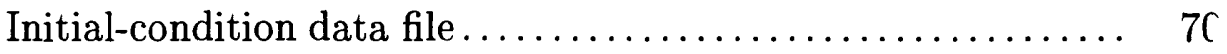

Boundary-condition data file $\ldots \ldots \ldots \ldots \ldots \ldots \ldots \ldots \ldots, 7 \AA$

Addendum to section 9. Output data description-depth-

averaged flow module: FLOMOD $\ldots \ldots \ldots \ldots \ldots \ldots \ldots \ldots \ldots, 7 i$

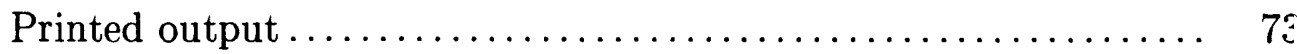

Output data files-flow data file $\ldots \ldots \ldots \ldots \ldots \ldots \ldots \ldots \ldots, 7 \varepsilon$

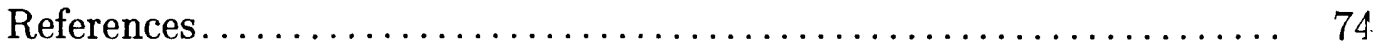




\section{FIGURES}

Page

Figures 4.1-4.4. Sketches showing:

4.1. Conceptual representation of surface-water/ground-water interconnection ........................... $\epsilon$

4.2. Finite-element network with levee segments, a weir

segment, and a culvert........................ $\varepsilon$

4.3. Levee cross section .............................

4.4. Definition of levee-seepage parameters................ 11

\section{TABLE}

Page

Table 4.1. Definition of the function $f \ldots \ldots \ldots \ldots \ldots \ldots \ldots \ldots \ldots, 12$ 


\section{CONVERSION FACTORS}

\begin{tabular}{rcl}
\hline \multicolumn{1}{c}{ Multiply } & By & \multicolumn{1}{c}{ To obtain } \\
\hline inch (in) & 25.40 & millimeter $(\mathrm{mm})$ \\
inch per hour (in/h) & 25.40 & millimeter per hour $(\mathrm{mm} / \mathrm{h})$ \\
inch per day (in/d) & 25.40 & millimeter per day $(\mathrm{mm} / \mathrm{d})$ \\
foot $(\mathrm{ft})$ & 0.3048 & meter $(\mathrm{m})$ \\
foot per second $(\mathrm{ft} / \mathrm{s})$ & 0.3048 & meter per second $(\mathrm{m} / \mathrm{s})$ \\
foot per square second & 0.3048 & meter per square second \\
$\left(\mathrm{ft} / \mathrm{s}^{2}\right)$ & & $\left(\mathrm{m} / \mathrm{s}^{2}\right)$ \\
square foot $\left(\mathrm{ft}^{2}\right)$ & 0.09290 & square meter $\left(\mathrm{m}^{2}\right)$ \\
square foot per second & 0.09290 & square meter per second \\
$\left(\mathrm{ft}^{2} / \mathrm{s}\right)$ & & $\left(\mathrm{m}^{2} / \mathrm{s}\right)$ \\
cubic foot per second $\left(\mathrm{ft}^{3} / \mathrm{s}\right)$ & 0.02832 & cubic meter per second $\left(\mathrm{m}^{3} / \mathrm{s}\right)$ \\
second per foot $(\mathrm{s} / \mathrm{ft})$ & 3.281 & second per meter $(\mathrm{s} / \mathrm{m})$ \\
slug per cubic foot & 515.7 & kilogram per cubic meter \\
$\left(\mathrm{slug} / \mathrm{ft}^{3}\right)$ & & $\left(\mathrm{kg} / \mathrm{m}^{3}\right)$ \\
\hline
\end{tabular}




\section{FINITE-ELEMENT SURFACE-WATER}

MODELING SYSTEM:

TWO-DIMENSIONAL FLOW

IN THE HORIZONTAL PLANE-

ADDENDUM TO THE USERS MANUAL

By Jonathan K. Lee

\section{Abstract}

This manual provides users of the Finite-Element Surface-Water Modeling System: Two-Dimensional Flow in the Horizontal Plane (FESWMS-2DH) the information necessary to use new additions and modifications to the original flow model, for which a users manual was published by Froehlich in 1989. This information includes descriptions of the basic logic of the changes, the necessary input data, and the output generated by the modeling system.

The modified or added features described in this manual include element source/sink terms for precipitation, evapotranspiration, and ground-water inflow, or outflow, or both; linearized friction in the momentum equations; sheltering coefficients added to surface-shear-stress terms to account for the reduced effect of wind due to emergent vegetation; seepage through and under levee segments; water-surface elevations outside the model domain for use with culverts, weir segments, and levee segments; modification with time of turbulence-model coefficients, friction coefficients, wind, vegetation characteristics, precipitation rate, evapotranspiration rate, ground-water-seepage parameters, ground-water heads, and boundary conditions, including total flows and water-surface elevations at specified cross sections, and external water-surface elevations at culverts, weir segments, and levee segments; optional formats for element incidence lists; and optional formats for the flowdata file. 


\section{Introduction}

This manual provides users of the Finite-Element Surface-Water Modeling System: Two-Dimensional Flow in the Horizontal Plane (FESWMS$2 \mathrm{DH})$ the information necessary to use new additions and modifications to the original flow model. The original users manual (Froehlich, 1989) describes three related FORTRAN programs: DINMOD, the data-input module; FLOMOD, the solution module; and ANOMOD, the output-analysis module. DINMOD is used to prepare a finite-element network, FLOMOD is used to obtain the water depth and depth-averaged flow velocity at the nodes of a finite-element network, and ANOMOD is used to create plots of model results.

The information presented in this manual includes descriptions of the basic logic of the changes made to the original version of FLOMOD, the necessary input data, and the output generated by the solution module. The modified or added features described in this manual include:

- Element source/sink terms for precipitation, evapotranspiration, and ground-water inflow, or outflow, or both

- Linearized friction in the momentum equations

- Sheltering coefficients added to surface-shear-stress terms to account for the reduced effect of wind due to emergent vegetation

- Seepage through and under levee segments

- Water-surface elevations outside the model domain for use with culverts, weir segments, and levee segments

- Modification with time of turbulence-model coefficients, friction coefficients, wind, vegetation characteristics, precipitation rate, evapotranspiration rate, ground-water-seepage parameters, ground-water heads, and boundary conditions, including total flows and water-surface elevations at specified cross sections, and external water-surface elevations at culverts, weir segments, and levee segments

- Optional formats for element incidence lists

- Optional formats for the flow-data file 
Modifications and additions to the flow equations are presented in the addendum to Section 4 . This information will help the user understand the new capabilities of the system, how required empirical coefficients are used, and how results are obtained. The addendum to Section 5 describes how new boundary conditions are incorporated into constraint equations at model boundaries. The addendum to Section 6 provides additional information on developing a finite-element network. A complete description of the input data needed to run FLOMOD is given in the addendum to Section 8 . The addendum to Section 9 describes modifications to the printed output and the flow-data file.

The units of dimensioned parameters and variables are given in the text in terms of length (L), time (T), and mass (M). Equations referenced in the original users manual are written with a hyphen (for example, 4-14); those in this report are written with a period (for example, 4.14).

\section{Addendum to Section 4. Governing Equations}

The two-dimensional, depth-averaged surface-water-flow equations are modified by the addition of source/sink terms for precipitation, evapotranspiration, and ground-water inflow, or outflow, or both. The capability to use linearized bed-shear-stress terms is added, and the surface-shear-stress terms are modified to treat water-surface sheltering by emergent vegetation. Equations used to model one-dimensional flow through and under permeable levees are described.

\section{Depth-Averaged Flow Equations}

The depth-averaged flow equations consist of equations for the conservation of momentum in the $x$ - and $y$-directions, equations $4-2$ and $4-3$ in the orginal manual (Froehlich, 1989), and an equation for conservation of mass, equation $4-4$ in the original manual.

\section{Bed Shear Stress}

Linear bed-friction terms in the momentum equations are useful in testing models and in initiating simulations. The directional components, $\tau_{x}^{b}$ and $\tau_{y}^{b}$, 
of the bed shear stress $\left(\mathrm{M} / \mathrm{LT}^{2}\right)$, given in the original manual by equations $4-9$ and $4-10$, are replaced by

$$
\tau_{x}^{b}=\rho c_{f} \sqrt{g H} U\left[1+\left(\frac{\partial z_{b}}{\partial x}\right)^{2}+\left(\frac{\partial z_{b}}{\partial y}\right)^{2}\right]^{1 / 2}
$$

and

$$
\tau_{y}^{b}=\rho c_{f} \sqrt{g H} V\left[1+\left(\frac{\partial z_{b}}{\partial x}\right)^{2}+\left(\frac{\partial z_{b}}{\partial y}\right)^{2}\right]^{1 / 2},
$$

where $\rho=$ density of water $\left(\mathrm{M} / \mathrm{L}^{3}\right), c_{f}=$ bed-friction coefficient (dimensionless), $g=$ gravitational acceleration (L/ $\left.\mathrm{T}^{2}\right), H=$ flow depth $(\mathrm{L}), U=$ depth-averaged velocity in the $x$-direction $(\mathrm{L} / \mathrm{T}), V=$ depth-averaged velocity in the $y$-direction $(\mathrm{L} / \mathrm{T})$, and $z_{b}=$ bed elevation $(\mathrm{L})$.

The linear bed-friction coefficient, $c_{f}$, is computed as

$$
c_{f}=\sqrt{g H} k_{f}
$$

where $k_{f}=$ linear friction coefficient $(\mathrm{T} / \mathrm{L})$. The expression $\sqrt{H}$ appearing in equations $4.1,4.2$, and 4.3 results because the momentum equations are solved in a conservative form, obtained in part by multiplying the nonconservative momentum equations by $H$. Appropriate values of $k_{f}$ can be estimated by substituting representative values of $n, H, U$, and $V$ into the equation

$$
k_{f}=\frac{n^{2}}{\phi H^{4 / 3}}\left(U^{2}+V^{2}\right)^{1 / 2}
$$

where $n=$ Manning's roughness coefficient $\left(\mathrm{T} / \mathrm{L}^{1 / 3}\right)$ and $\phi=2.208$ wher inch/pound units are used and 1.0 when International System (SI) units are used. The coefficient $k_{f}$ is allowed to vary in space and time.

\section{Surface Shear Stress}

The directional components, $\tau_{x}^{s}$ and $\tau_{y}^{s}$, of the surface shear stress (M/LT $\left.{ }^{2}\right)$ are given in the original manual by equations 4-13 and 4-14. To account for the sheltering effect of emergent vegetation, $\tau_{x}^{s}$ and $\tau_{y}^{s}$ are multiplied by $c_{\text {. }}$ 
dimensionless sheltering coefficient, $S$, defined by Reid and Whitaker (1976, p. 64) for $h_{v}>H$ as

$$
S=\frac{1}{1+\frac{c_{v} N_{v} w_{v}\left(h_{v}-H\right)}{c_{s}}},
$$

where $c_{v}=$ vegetation drag coefficient (dimensionless); $N_{v}=$ plant density, in stems or leaves per unit area $\left(1 / \mathrm{L}^{2}\right) ; w_{v}=$ average stem or leaf width $(\mathrm{L}) ; h_{v}=$ average stem or leaf height $(\mathrm{L})$; and $c_{s}=$ surface-stress coefficient (dimensionless). The parameters $c_{v}, N, w_{v}$, and $h_{v}$ are allowed to vary in space and time. Assigning a value to $c_{s}$ is discussed in the original manual, and assigning a value to $c_{v}$ is discussed in Reid and Whitaker $(1976$, p. 68). If $h_{v} \leq H, S$ is assigned the value 1.0.

\section{Source/Sink Terms}

The symbol $q$, which is used to denote source/sink terms (L/T) in the mass-conservation equation, is subtracted from the left-hand side of equation 4-4 given in the original manual. This term can be expanded to represent precipitation, evapotranspiration, and ground-water inflow, or outflow, or both. Thus,

$$
q=q_{p}-q_{e}+q_{g}
$$

where $q_{p}=$ precipitation rate $(\mathrm{L} / \mathrm{T}) ; q_{e}=$ evapotranspiration rate $(\mathrm{L} / \mathrm{T})$; and $q_{g}=$ ground-water-inflow or -outflow rate $(\mathrm{L} / \mathrm{T})$, positive for inflow and negative for outflow. These rates are permitted to vary in space and time.

\section{Ground-Water Inflow/Outflow}

Seepage between surface water and ground water, $q_{g}$, is expressed as in McDonald and Harbaugh (1988, chap. 6). The surface water is assumed to be separated from the ground water by a low-permeability layer of material of thickness $M_{\ell}$ (L) (fig. 4.1). The hydraulic conductivity of this layer is denoted by $K_{\ell}(\mathrm{L} / \mathrm{T})$. If it is further assumed that all head losses between the surface water and the aquifer are across the low-permeability layer and that the piezometric head of the ground water is above the bottom of the low-permeability layer, then the flow $q_{g}$ between the surface water and the 


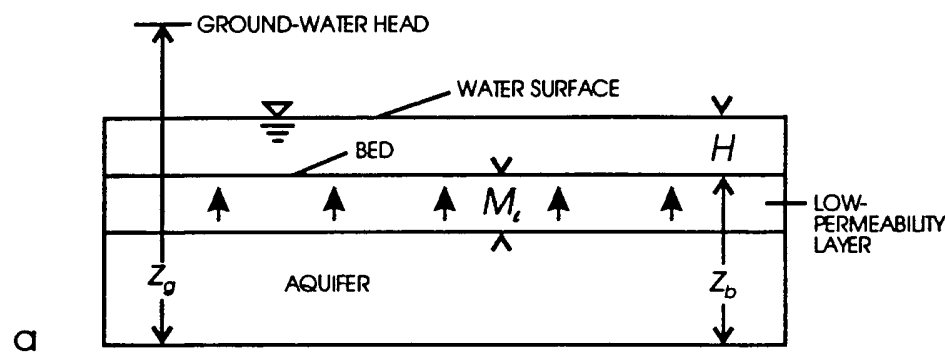

\section{EXPLANATION}

$Z_{b}$ BED ELEVATION

$Z_{\sigma}$ GROUND-WATER-HEAD

$H$ FLOW DEPTH

$M$ I TICKNESS OF $1 O W$

PERMEABIUTY LAYER

DIRECTON OF GROUNDWATER FLW

b
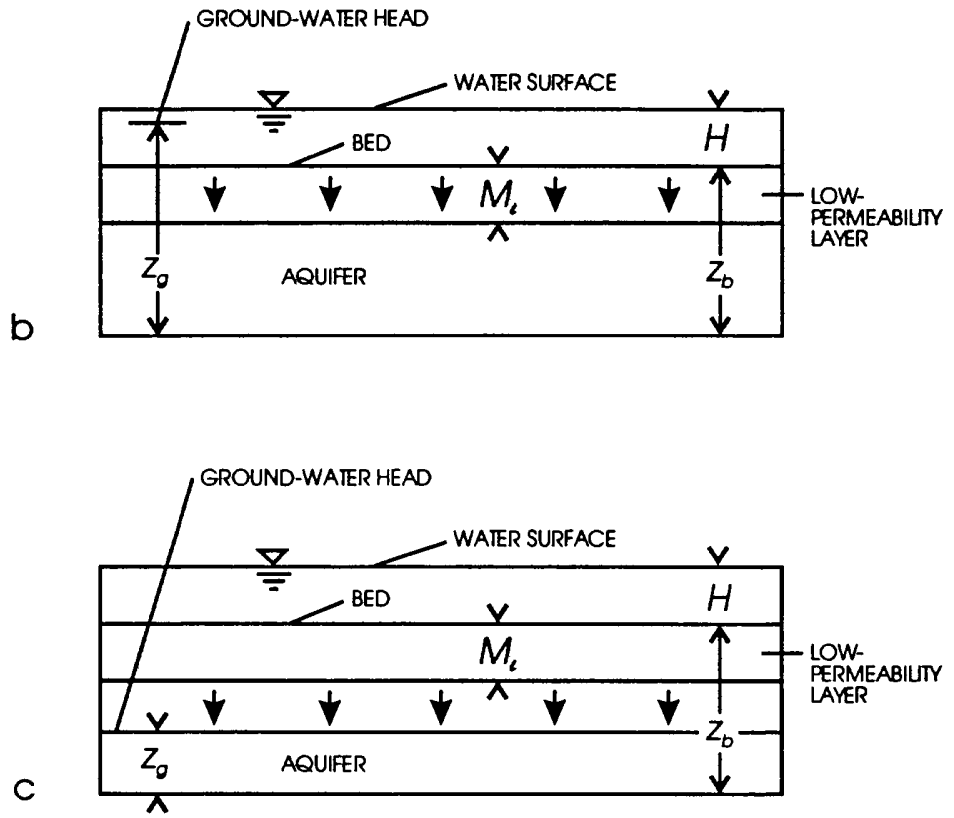

Figure 4.1: Conceptual representation of surface-water/ground-water interconnection with (a) the ground-water head above the surface-water elevation, (b) the ground-water head below the surface-water elevation but above the bottom of the low-permeability layer, and (c) the ground-water head below the bottom of the low-permeability layer. 
aquifer is given by

$$
q_{g}=\frac{K_{\ell}}{M_{\ell}}\left(z_{g}-z_{b}-H\right)=C_{\ell}\left(z_{g}-z_{b}-H\right),
$$

where $C_{\ell}=K_{\ell} / M_{\ell}=$ hydraulic conductance of the low-permeability layer $(1 / \mathrm{T})$ and $z_{g}=$ ground-water head $(\mathrm{L})$. Note that $q_{g}$ is positive (the flow is from the ground water to the surface water) if $z_{g}>z_{b}+H$ and $q_{g}$ is negative if $z_{g}<z_{b}+H$. As discussed in McDonald and Harbaugh (1988, chap. 6), if the ground-water level falls below a certain point, seepage from the surface water to the ground water no longer depends on the ground-water head. If the water level in the aquifer falls below the base of the low-permeability layer and if it is assumed that the low-permeability layer remains saturated, then the head at its base is the elevation of that point. Because the elevation of the base of the low-permeability layer is $z_{b}-M_{\ell}$, the flow $q_{g}$ from the surface water to the ground water is

$$
q_{g}=C_{\ell}\left(z_{b}-M_{\ell}-z_{b}-H\right)=-C_{\ell}\left(M_{\ell}+H\right) .
$$

Equations 4.7 and 4.8 can be combined to give

$$
q_{g}=\left\{\begin{array}{cl}
C_{\ell}\left(z_{g}-z_{b}-H\right) & \text { if } z_{g}>z_{b}-M_{\ell}, \\
-C_{\ell}\left(M_{\ell}+H\right) & \text { if } z_{g} \leq z_{b}-M_{\ell} .
\end{array}\right.
$$

\section{Flow Through and Under Levees}

Seepage flow through and under levees can have a appreciable effect on the mass balance in a wetland system. One-dimensional seepage flow through and under a levee is modeled by dividing the levee into sections called levee segments. Each levee segment is described by either one or two boundary nodes and the base width, top width, height, and length of the levee segment. If water is allowed to flow under the levee, the thickness of the levee-segment sublayer must be given. Additionally, the permeabilities of the levee segment and the sublayer are required. Two boundary nodes are needed, one on each side of the segment, if the areas on both sides of the levee segment are included in the finite-element network. Water that flows through or under a levee segment defined by two boundary nodes (fig. 4.2) leaves the network at the upstream node (the node with the higher water-surface elevation) and 


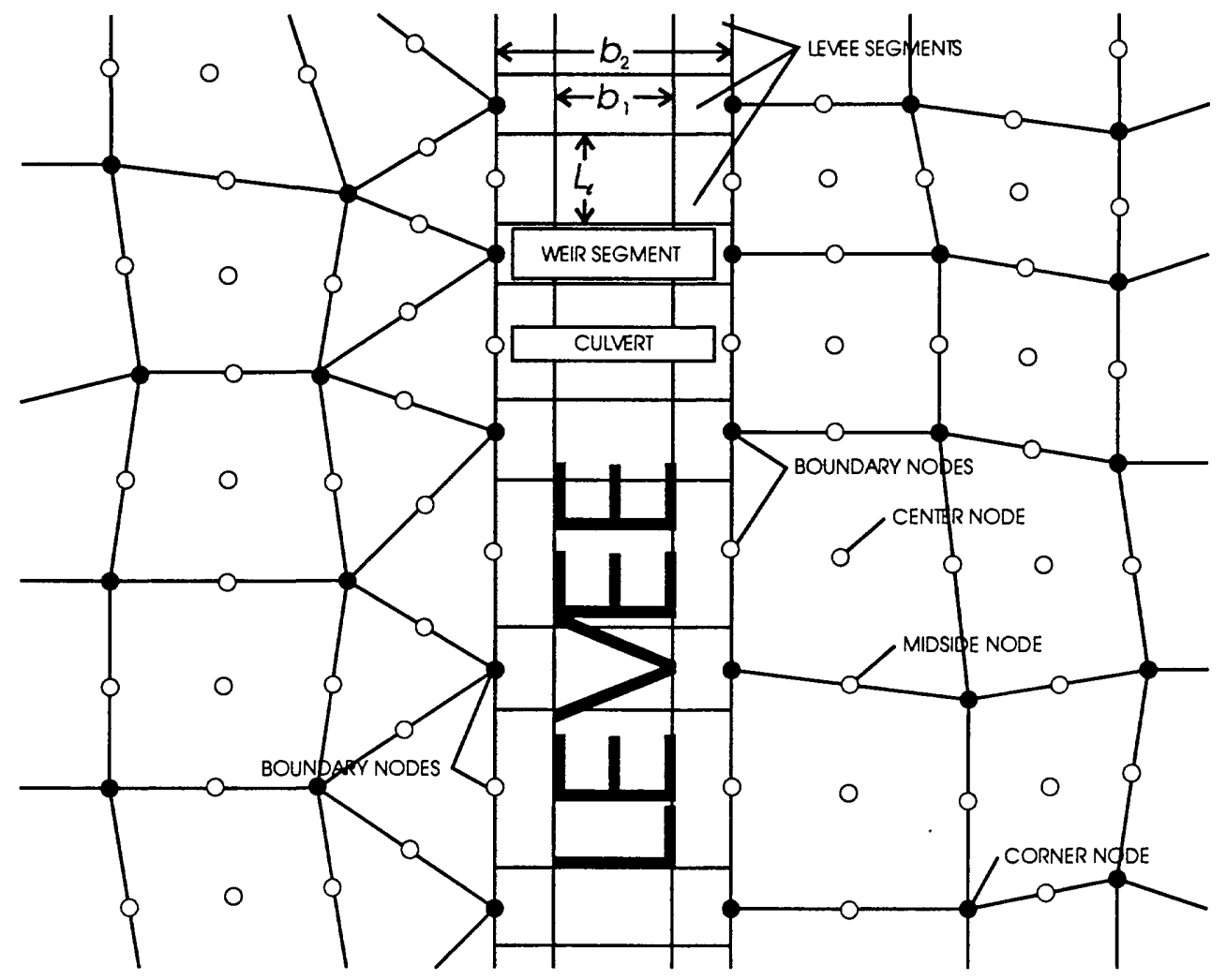

EXPLANATION

b, TOP WDTH OF LEVEE SEGMENT

$b_{2}$ BASE MDTH OF LEVEE SEGMENT

L. LENGTH OF LEVEE SEGMENT

Figure 4.2: Finite-element network with levee segments, a weir segment, anc a culvert. 


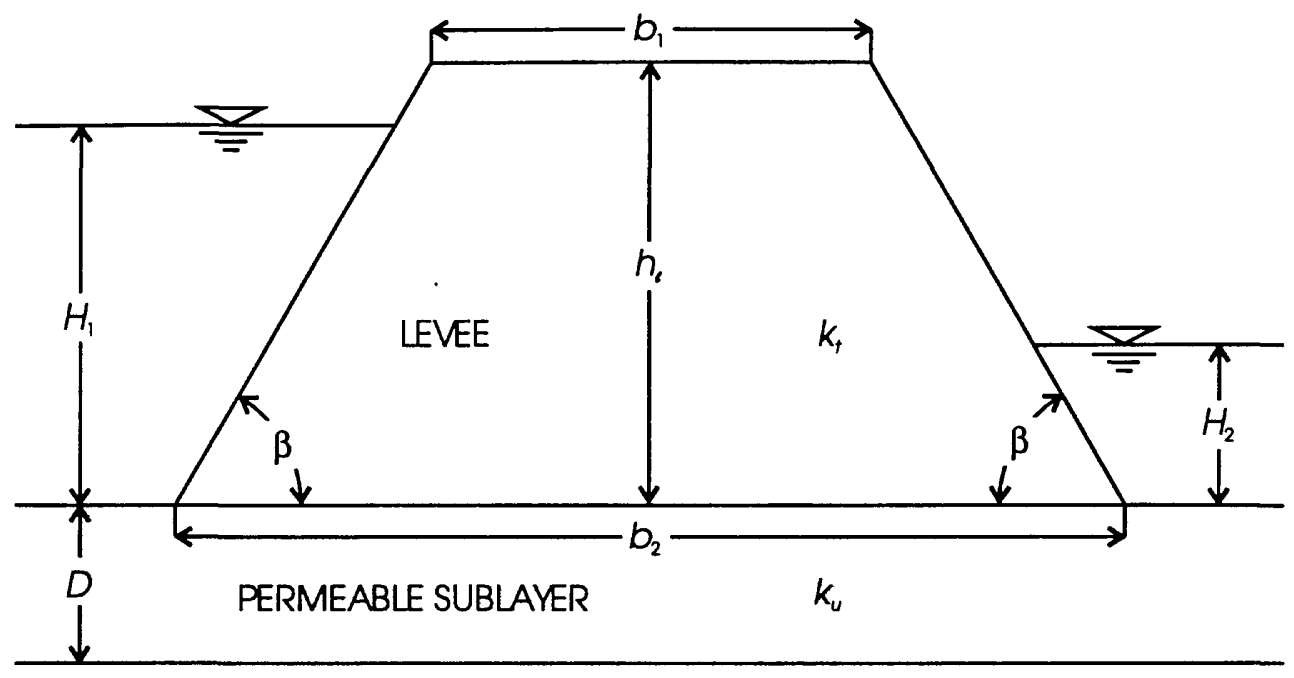

\section{EXPLANATION}

$\begin{array}{ll}b_{1} & \text { TOP MDTH OF LEVEE } \\ b_{2} & \text { BASE MDTH OF LEVEE } \\ h_{c} & \text { HEIGHT OF LEVEE } \\ k_{t} & \text { PERMEABIUTY OF LEVEE } \\ k_{u} & \text { PERMEABIUTY OF SUBLAYER }\end{array}$

$D$ THICKNESS OF PERMEABLE SUBLAYER

$H_{1}$ FLOW DEPTH UPSTREAM RROM LEVEE

$\mathrm{H}_{2}$ FLW DEPTH DOWNSTREAM FROM LEVEE

$\beta$ ANGLE BETWEEN HORIZONTAL AND SIDE OF LEVEE

Figure 4.3: Levee cross section.

enters the network at the downstream node. If the area on only one side of a levee segment is included in the network, only one boundary node is needed for each levee segment. In this case, the water-surface elevation outside the network must be specified, and flow into or out of the network is determined on the basis of the interior and specified exterior water-surface elevations. Levee segments, weir segments, and culverts may share the same nodes, as shown in figure 4.2 .

A definition sketch of the cross section of a permeable levee with a permeable sublayer is shown in figure 4.3. The angle, $\beta$, between the horizontal and the side of the levee is assumed to be the same for both sides. Then

$$
\tan \beta=\frac{2 h_{\ell}}{b_{2}-b_{1}}
$$


or

$$
\beta=\arctan \left(\frac{2 h_{\ell}}{b_{2}-b_{1}}\right),
$$

where $h_{\ell}=$ height of the levee $(\mathrm{L}), b_{2}=$ base width of the levee $(\mathrm{L})$, and $b_{1}=$ top width of the levee (L). The symbol $D$ denotes the thickness of the permeable sublayer (L), and $k_{t}$ and $k_{u}$ denote the permeabilities of the levee and the sublayer, respectively $(\mathrm{L} / \mathrm{T})$.

Peter (1982, p. 123) presents the following equation for the total seepage flow, $q$, per unit length of levee segment $\left(\mathrm{L}^{2} / \mathrm{T}\right)$ :

$$
q_{\ell}=q_{t}+q_{u}
$$

where

$$
q_{t}=k_{t} \frac{H_{1}^{2}-H_{2 s}^{2}}{2 d}
$$

and (Department of the Army, 1978, p. B-13)

$$
q_{u}=k_{u} \frac{\left(H_{1}-H_{2}\right) D}{b_{2}\left(1+0.86 \frac{D}{b_{2}}\right)}
$$

Here, $q_{t}$ and $q_{u}=$ seepage flow per unit length through and under the levee segment, respectively $\left.\left(\mathrm{L}^{2} / \mathrm{T}\right)\right) ; H_{1}=$ depth of water on the upstream side of the levee segment $(\mathrm{L}) ; H_{2}=$ depth of water on the downstream side of the levee segment $(\mathrm{L})$; and

$$
H_{2 s}=H_{s}+H_{2} \text {, }
$$

where $H_{s}=$ height above the downstream water surface at which the seepage surface emerges on the downstream face of the levee (L) (fig. 4.4). It can be shown (Peter, 1982, p. 107) that the lower part of the seepage surface can be approximated by a parabola. The variable $d$ in equation 4.13 is the length (L) of the projection on the horizontal of the line connecting the focus of the parabola and the point where the tangent of inflection to the parabola intersects the water surface (fig. 4.4). Thus, $d$ can be approximated as

$$
d=0.3 s_{1}+s_{2}+b_{1}+s_{3}-s_{4}
$$




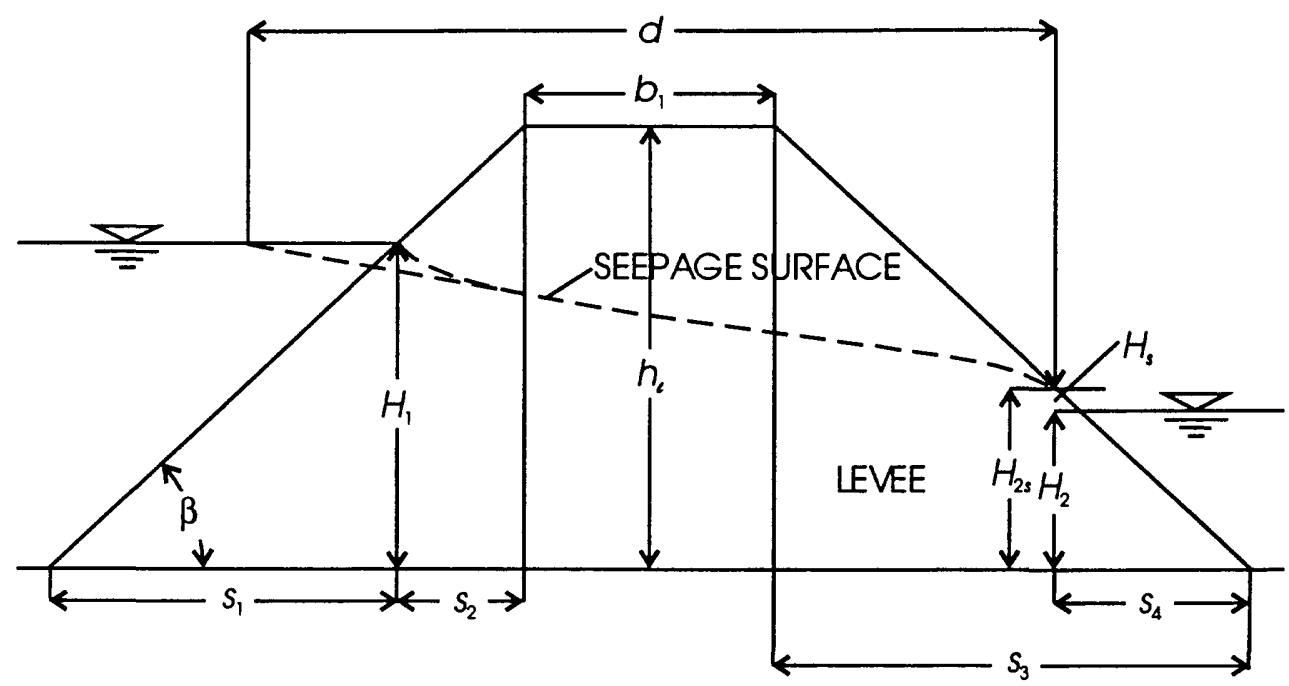

\section{EXPLANATON}

$b$, TOP MDTH OF LEVEE

d VARIABLE DEFINED IN EQUATION 4.16

$h_{c}$ HEIGHT OF LEVEE

$S_{1}$ VARIABLE DEFNED IN EQUATION 4.17

$S_{2}$ VARIABLE DEFNED IN EQUATON 4.18

$S_{3}$ VARIABLE DEFNED IN EQUATION 4.19
$S_{4}$ VARIABLE DEFINED IN EQUATION 4.20
$H_{1}$ FLOW DEPTH UPSTREAM RROM LEVEE
$\mathrm{H}_{2}$ FLOW DEPTH DOWNSTREAM RROM LEVEE
$H_{2 s}$ VARIABLE DEFNED IN EQUATION 4.15
$H_{s}$ VARIABLE DEFNED IN EQUATION 4.21
$\beta$ ANGLE BETWEEN HORIZONTAL AND SIDE OF LEVEE

Figure 4.4: Definition of levee-seepage parameters. 
Table 4.1. Definition of the function $f$.

\begin{tabular}{cc}
\hline $\begin{array}{c}\text { Angle } \beta, \\
\text { in degrees }\end{array}$ & $\begin{array}{c}f(\beta), \\
\text { dimensionless }\end{array}$ \\
\hline 10 & 10.45 \\
20 & 4.14 \\
25 & 2.78 \\
30 & 2.11 \\
40 & 1.60 \\
50 & 1.26 \\
60 & 1.00 \\
70 & .83 \\
90 & .63 \\
\hline
\end{tabular}

The terms of equation 4.16 can be written as

$$
\begin{gathered}
s_{1}=H_{1} \cot \beta, \\
s_{2}=\left(h_{\ell}-H_{1}\right) \cot \beta, \\
s_{3}=h_{\ell} \cot \beta,
\end{gathered}
$$

and

$$
s_{4}=\left(H_{2}+H_{s}\right) \cot \beta=H_{2 s} \cot \beta,
$$

where

$$
H_{s}=f(\beta) \frac{\left(H_{1}-H_{2}\right)^{2}}{b_{1}+b_{2}}
$$

and the function $f$ (Peter, 1982, p. 111) is defined in table 4.1. Substituting: equations 4.17 through 4.21 into equation 4.16 gives

$$
d=b_{1}+\cot \beta\left[2 h_{\ell}-0.7 H_{1}-H_{2}-f(\beta) \frac{\left(H_{1}-H_{2}\right)^{2}}{b_{1}+b_{2}}\right] .
$$

By equations $4.13,4.15,4.21$, and 4.22 ,

$$
q_{t}=k_{t} \frac{H_{1}^{2}-\left[H_{2}+f(\beta) \frac{\left(H_{1}-H_{2}\right)^{2}}{b_{1}+b_{2}}\right]^{2}}{2\left\{b_{1}+\cot \beta\left[2 h_{\ell}-0.7 H_{1}-H_{2}-f(\beta) \frac{\left(H_{1}-H_{2}\right)^{2}}{b_{1}+b_{2}}\right]\right\}} .
$$




\section{Addendum to Section 5. Finite-Element Equations}

\section{Residual Expressions}

The residual at node $i$ of the mass-conservation equation is given in equation 5-3 of the original manual (Froehlich, 1989). The source/sink terms given in equation 4.6 are subtracted from the terms inside the square brackets of equation 5-3.

\section{Derivative Expressions}

The only source/sink term contributing to a derivative expression for the mass-conservation equation is the ground-water inflow or outflow term. The term $C_{\ell}$ is added to the terms inside the first pair of square brackets of equation 5-20, the derivative of the residual of the mass-conservation equation at node $i$ with respect to the depth, $H_{j}$, at node $j$.

\section{Application of Boundary and Special Conditions- Total Flow Across a Boundary}

Modifying equation 5-35 of the original manual (Froehlich, 1989), flow across a closed boundary (referred to as a solid boundary in the orginal manual) at node $i$ can be represented as

$$
Q_{i}^{c}=Q_{s i}^{c}+Q_{w i}+Q_{c i}+Q_{\ell i}
$$

where $Q_{i}^{c}=$ total flow across the closed boundary at node $i\left(\mathrm{~L}^{3} / \mathrm{T}\right), Q_{s i}^{c}=$ specified flow normal to the closed boundary at node $i\left(\mathrm{~L}^{3} / \mathrm{T}\right), Q_{w i}=$ total weir flow across the closed boundary at node $i\left(\mathrm{~L}^{3} / \mathrm{T}\right), Q_{c i}=$ total culvert flow across the closed boundary at node $i\left(\mathrm{~L}^{3} / \mathrm{T}\right)$, and $Q_{\ell i}=$ total levee-seepage flow across the closed boundary at node $i\left(\mathrm{~L}^{3} / \mathrm{T}\right)$.

The constraint equation for flow normal to the closed boundary at node $i$ is, from equation 5-39 in the original manual,

$$
f_{2 i}^{\prime}=a_{i}^{c} U_{i}+b_{i}^{c} V_{i}-Q_{i}^{c}=0,
$$


where $a_{i}^{c}, b_{i}^{c}=$ coefficients defined by equations 5-44 and 5-45 in the original manual $\left(\mathrm{L}^{2}\right)$ and $U_{i}, V_{i}=$ depth-averaged velocity components at nod $\epsilon$ $i(\mathrm{~L} / \mathrm{T})$. Partial Newton-Raphson iteration is used to treat the constraint equation; that is, only one nodal depth at a time is treated as variable in the constraint equation; the other nodal depth, if it exists, is treated as constant and is given the value obtained during the previous iteration. However, when two nodes are involved, each constraint equation appears twice, and each nodal depth will be variable in one of the equations.

The derivatives of the constraint equation with respect to $U_{j}$ and $V_{j}$ are given by equations 5-51 and 5-52 of the original manual, and the derivative of the constraint equation with respect to $H_{j}$ becomes

$$
\frac{\partial f_{2 i}^{\prime}}{\partial H_{j}}=\frac{\partial a_{i}^{c}}{\partial H_{j}} U_{i}+\frac{\partial b_{i}^{c}}{\partial H_{j}} V_{i}-\frac{\partial Q_{w i}}{\partial H_{j}}-\frac{\partial Q_{c i}}{\partial H_{j}}-\frac{\partial Q_{\ell i}}{\partial H_{j}},
$$

where all the coefficients on the right-hand side of equation 5.3 except the last are given by equations 5-54 through 5-57 in the original manual. The expression $Q_{\ell i}$ in equations 5.1 and 5.3 can be written as

$$
Q_{\ell i}=L_{\ell i} q_{\ell i}=L_{\ell i}\left(q_{t i}+q_{u i}\right),
$$

where $L_{\ell i}=$ length of the levee segment at node $i(\mathrm{~L}), q_{\ell i}=$ flow per unit length through and under the levee segment at node $i\left(\mathrm{~L}^{2} / \mathrm{T}\right), q_{t i}=$ flow per unit length through the levee segment at node $i\left(\mathrm{~L}^{2} / \mathrm{T}\right)$, and $q_{u i}=$ flow per unit length under the levee segment at node $i\left(\mathrm{~L}^{2} / \mathrm{T}\right)$. To simplify the notation, the subscript $i$ is dropped in the remainder of this subsection. The numerator, $\mathcal{N}$, and the denominator, $\mathcal{D}$, of the expression for $q_{t}$ are, by equation 4.23 ,

$$
\mathcal{N}=k_{t}\left\{H_{1}^{2}-\left[H_{2}+f(\beta) \frac{\left(H_{1}-H_{2}\right)^{2}}{b_{1}+b_{2}}\right]^{2}\right\}
$$

and

$$
\mathcal{D}=2\left\{b_{1}+\cot \beta\left[2 h_{\ell}-0.7 H_{1}-H_{2}-f(\beta) \frac{\left(H_{1}-H_{2}\right)^{2}}{b_{1}+b_{2}}\right]\right\} .
$$

Now assume that the nodal variable $H_{j}=H_{1}$, the depth corresponding tc the higher water-surface elevation at the levee segment. Then, by equations 
$5.4,5.5,5.6$, and 4.14 ,

$$
\frac{\partial Q_{\ell}}{\partial H_{j}}=\frac{\partial Q_{\ell}}{\partial H_{1}}=L_{\ell} \frac{\frac{\partial \mathcal{N}}{\partial H_{1}} \mathcal{D}-\mathcal{N} \frac{\partial \mathcal{D}}{\partial H_{1}}}{\mathcal{D}^{2}}+L_{\ell} k_{u} \frac{D}{b_{2}\left(1+0.86 \frac{D}{b_{2}}\right)}
$$

where

$$
\frac{\partial \mathcal{N}}{\partial H_{1}}=k_{t}\left\{2 H_{1}-2\left[H_{2}+f(\beta) \frac{\left(H_{1}-H_{2}\right)^{2}}{b_{1}+b_{2}}\right]\left[2 f(\beta) \frac{H_{1}-H_{2}}{b_{1}+b_{2}}\right]\right\}
$$

and

$$
\frac{\partial \mathcal{D}}{\partial H_{1}}=2 \cot \beta\left[-0.7-2 f(\beta) \frac{H_{1}-H_{2}}{b_{1}+b_{2}}\right] .
$$

If $H_{j}=H_{2}$, the depth corresponding to the lower water-surface elevation at the levee segment, then

$$
\frac{\partial Q_{\ell}}{\partial H_{j}}=\frac{\partial Q_{\ell}}{\partial H_{2}}=L_{\ell} \frac{\frac{\partial \mathcal{N}}{\partial H_{2}} \mathcal{D}-\mathcal{N} \frac{\partial \mathcal{D}}{\partial H_{2}}}{\mathcal{D}^{2}}-L_{\ell} k_{u} \frac{D}{b_{2}\left(1+0.86 \frac{D}{b_{2}}\right)}
$$

where

$$
\frac{\partial \mathcal{N}}{\partial H_{2}}=-2 k_{t}\left[H_{2}+f(\beta) \frac{\left(H_{1}-H_{2}\right)^{2}}{b_{1}+b_{2}}\right]\left[1-2 f(\beta) \frac{H_{1}-H_{2}}{b_{1}+b_{2}}\right]
$$

and

$$
\frac{\partial \mathcal{D}}{\partial H_{2}}=2 \cot \beta\left[-1+2 f(\beta) \frac{H_{1}-H_{2}}{b_{1}+b_{2}}\right]
$$

\section{Addendum to Section 6. Modeling System Operation}

\section{Data Collection}

Additional data may be required if the optional model features described in this addendum are to be used in model implementation. These data 
may include vegetation characteristics (for wind-sheltering effects), precipitation rates, and evapotranspiration rates. If ground-water seepage is tc be considered, the thickness and conductance of the low-permeability layer and ground-water heads must be obtained. Modeling levee seepage requires collection of geometric data, permeabilities, and, possibly, water-surface elevations outside the network.

\section{Network Design}

\section{General Network Layout}

After model boundaries have been defined, as discussed in the orginal manual, a map of the water body to be modeled is obtained. The scale and detail of the base map depend on the detail and accuracy sought in the solution. A series of overlays of the base map are made. On each overlay, the model domain is subdivided into relatively large subdomains, in eack of which a model parameter or set of parameters is approximately uniform. The parameters or parameter sets for turbulence, friction, and, optionally, vegetation, precipitation, evapotranspiration, and ground-water seepage are considered in this process. The subdivision lines between the regions are located, as much as possible, where abrupt changes in the selected parameter or parameter set occur. The union of all the subdivision lines defined by this series of overlays is used as the basis for further subdivision of the model domain into elements. The series of overlays can be used as the basis for defining element codes for turbulence, friction, vegetation, precipitation, evapotranspiration, and ground-water seepage.

\section{One-Dimensional Levees}

One-dimensional seepage flow through and under a levee is treated as $\varepsilon$. point flow on the boundary of a finite-element network. A point flow is the total flow that crosses the network boundary because of flow at a single node. A one-dimensional levee segment is described by a set of parameters and two nodes, one on each side of the levee, if the areas on both sides of the levee segment are included in the finite-element network, or one node, if only one side of the levee segment is included in the network. Flow through and under the levee segment is computed on the basis of the water-surface elevations 
at the two nodes (or the water-surface elevation at the interior node and a specified external water-surface elevation). The following items must be specified for each levee segment (see figs. 4.2 and 4.3): (1) the base width of the levee segment $\left(b_{2}\right),(2)$ the top width of the levee segment $\left(b_{1}\right),(3)$ the height of the levee segment $\left(h_{\ell}\right),(4)$ the length of the levee segment $\left(L_{\ell}\right),(5)$ the thickness of the levee-segment sublayer $(D),(6)$ the permeability of the levee segment $\left(k_{t}\right)$, and (7) the permeability of the levee-segment sublayer $\left(k_{u}\right)$.

To model flow through and under a levee contained within the flow domain, the finite-element network must be designed so that closed boundaries are located on both sides of the levee. The levee is divided into a number of levee segments, and appropriate parameters are assigned to each segment. The number of segments used to divide the levee depends on the variation of the levee geometry and permeability and the spacing of the nodes on the closed boundaries that define the levee. Nodes that define the sides of a levee segment must be located approximately at the center of the levee segment. Flow will be allowed to leave the network at the upstream node (the node with the higher water-surface elevation) and reenter the network at the downstream node. If only one side of the levee is included in the finite-element network, flow through and under the levee will be determined on the basis of the interior water-surface elevation and a specified exterior water-surface elevation. The determination of levee segments is governed by the considerations discussed above. The location of levee segments must be considered during the initial design of a finite-element network. It is good practice to align nodes on opposite sides of a levee as shown in figure 4.2. A single point can be used to define the side or end of more than one weir segment, culvert, or levee segment, as shown in figure 4.2.

Assigning two-thirds of the side length of an element to the midside node and one-sixth of the side length to each vertex node of that side will result in equal flows across the network boundary at each of the nodes if watersurface elevations and levee parameters are constant along the element side. The lengths of levee segments assigned in this manner will alternate in size. 


\section{Addendum to Section 8. Input Data Descrip- tion}

\section{Depth-Averaged Flow Module: FLOMOD}

Several new features are found in the input data to FLOMOD, the FORTRAN solution module. Input element incidence lists can be read in either IF or I6 format. The element-property code and data set are replaced with separate element-property codes and data sets for turbulence-model coefficients. friction coefficients, vegetation characteristics, precipitation rate, evapotranspiration rate, and ground-water-seepage parameters. A linearized frictior coefficient is added to the friction data set. Levee and ground-water-heac data sets are added. General wind and ground-water-head data are added tc the time-dependent data set. Updated turbulence-model coefficients, frictior coefficients, wind data, vegetation characteristics, precipitation rate, evapotranspiration rate, ground-water-seepage parameters, ground-water heads. and boundary conditions, including total flows and water-surface elevations at specified cross sections, and external water-surface elevations at boundary culverts, weir segments, and levee segments, can be read at any time step. Finally, several errors and omissions in the input data description of the original users manual are corrected.

Data sets read by FLOMOD are preceded by the following identification records.

\section{DATA-SET IDENTIFICATION RECORD}

$\begin{array}{lll}\text { Variable IDS } & & \text { Data to be entered } \\ & \text { SWMS } & \\ \text { ELEM } & & \text { Program-control data } \\ \text { NODE } & & \text { Element data } \\ \text { TURB } & & \text { Node data } \\ \text { FRIC } & \text { Turbulence-model data } \\ \text { WIND } & \text { Friction data } \\ \text { VEGE } & \text { Wind data } \\ \text { PREC } & \text { Vegetation data } \\ & \text { Precipitation data }\end{array}$




\section{Variable IDS $\quad \underline{\text { Data to be entered }}$}

$\begin{array}{ll}\text { EVAP } & \text { Evapotranspiration data } \\ \text { GRWT } & \text { Ground-water-seepage data } \\ \text { HEAD } & \text { Ground-water-head data } \\ \text { INIT } & \text { Initial-condition data } \\ \text { BOUN } & \text { Boundary-condition data } \\ \text { QSEC } & \text { Total-flow-cross-section data } \\ \text { ZSEC } & \text { Water-surface-elevation-cross-section data } \\ \text { WEIR } & \text { Weir data } \\ \text { CULV } & \text { Culvert data } \\ \text { LEVE } & \text { Levee data } \\ \text { FLUX } & \text { Flow-check data } \\ \text { TIME }^{2} & \text { Time-dependent data } \\ \text { LAST }^{3} & \text { Last record in the input data stream }\end{array}$

\footnotetext{
${ }^{1}$ This must be the first data set in the input data stream.

${ }^{2}$ Time-dependent data sets must appear in chronological order at the end of the input data stream.

${ }^{3}$ This must be the last record in the input data stream.
} 


\section{Program-Control Data Set}

Program-control data records immediately follow an SWMS-data-set identification record. The identification record contains the data-set identification code and codes that control the width of the printed output, the printing of screen messages, and the formats of input element data and output flow data. The other six records of the data set contain information that controls the overall operation of the program. Record 1 contains a job title, which will be used in printed output headings. Record 2 contains job option codes. Record 3 contains input/output file specifications. Record 4 contains iteration control data and time-dependent-solution parameters. Record : contains general system specifications. Record 6 contains general wind and ground-water data.

\section{SWMS IDENTIFICATION RECORD-FORMAT(A4,6X,4E10.0)}

$\begin{array}{llll}\text { Columns } & \text { Variable } & \text { Value } & \text { Description } \\ 1 \text { to } 4 & \text { IDS } & \text { SWMS } & \begin{array}{l}\text { Program-control-data-set identification } \\ \text { code }\end{array}\end{array}$

5 to $10 \quad-\quad-\quad$ Not used

11 to 20 WIDE $0 \quad$ 80-column format will be used for printed output (default)

1 132-column output will be used for printed output

21 to 30 SCREEN 0 Messages that describe program operations will not be written to the terminal screen (default)

1 Messages that describe program operations will be written to the terminal screen 
$\underline{\text { Columns Variable Value Description }}$

31 to 40 GRIDF $\quad 0 \quad$ I5 format will be used for input element data (default)

1 I6 format will be used for input element data

41 to 50 FLOWF $\quad 0 \quad$ E10.3 format will be used for output flow data (default)

$1 \quad$ E12.5 format will be used for output flow data

SWMS RECORD 1-FORMAT(A80)

1 to 80 TITLE a/n Alphanumeric characters to be used in printed output headings. Usually the title will include the name of the water body being modeled

SWMS RECORD 2-FORMAT(15I5)

1 to 5 IDRUN 0 A normal steady-state or time-dependent solution will be performed

1 A restart/recovery run will be performed. Initial conditions will be read from a restart/recovery file. The default name of the restart/recovery file is RSRC.DAT

6 to 10 IPRNT 0 to 31 Sum of the following printed-output options that are desired: 


\section{Columns Variable Value Description}

Options

$0 \quad$ Control data, error messages, and solution results will be printed

$1 \quad$ All input data read from data records will be echo printed

$2 \quad$ Element and node data will be printed

$4 \quad$ Initial-condition data will be printed

$8 \quad$ Element assembly sequence will be printed

16 Degree-of-freedom array that contains equation numbers that correspond to each nodal variable will be printed

11 to 15 IUNIT $0 \quad$ Inch/pound units will be used in all computations and printed output

1 International System (SI) units will be used in all computations and printed output

16 to 20 IWIND 0 Wind-induced surface stresses will not be considered

1 Wind-induced surface stresses will be considered

21 to 25 IFRIC $\quad 0 \quad$ Bottom stresses will be computed using the Manning equation 
$\underline{\text { Columns Variable Value Description }}$

$1 \quad$ Bottom stresses will be computed using the Chézy equation

$2 \quad$ Bottom stresses will be computed using linearized friction

26 to 30 IVEGE $\quad 0 \quad$ Vegetative sheltering of the water surface from wind will not be considered

1 Vegetative sheltering of the water surface from wind will be considered

31 to 35 IPREC $0 \quad$ Precipitation will not be considered

$1 \quad$ Precipitation will be considered

36 to 40 IEVAP $0 \quad$ Evapotranspiration will not be considered

1 Evapotranspiration will be considered

41 to 45 IGRWT $0 \quad$ Ground-water seepage will not be considered

1 Ground-water seepage will be considered

46 to 50 ISLIP $\quad 0$

Slip (tangential-flow/zero-tangential-shear) conditions will be applied automatically at all closed-boundary nodes

$1 \quad$ No-slip (zero-flow) conditions will be applied automatically at all closedboundary nodes 


\section{$\underline{\text { Columns Variable Value Description }}$ \\ 51 to 55 IHINT 0 Low-order numerical integration will be used on all elements \\ 1 High-order numerical integration will be used on all curve-sided elements \\ 2 High-order numerical integration will be used on all elements}

56 to 60 INORM 0 to 3 Sum of the following continuity-norm options that are desired:

Options

$0 \quad$ Continuity norms will not be computed

1 Continuity norms will be computed at the end of a steady-state solution

2 Continuity norms will be computed at the end of every time step of a timedependent solution

61 to 65 IONOFF $0 \quad$ Elements will not be turned on and off during a run

$1 \quad$ Elements will be turned on and off during a run 


\section{$\underline{\text { Columns }}$ Variable Value Description}

Note: Use of the automatic-boundaryadjustment option allows elements that are not covered entirely by water to be included in a network. If IONOFF $=1$, all "dry" elements will be excluded from the "active" network

66 to 70 ISAVE 0

Files that contain the upper and lower decompositions of the coefficient matrix will be deleted at the end of a run

$1 \quad$ Files that contain the upper and lower decompositions of the coefficient matrix will be saved at the end of a run

71 to 75 NPVMIN $+\quad$ Minimum number of completed equations retained in the active matrix during a frontal solution. NPVMIN $>1$ provides a choice of pivotal coefficients but will increase the number of computations and the frontwidth of the system of equations. The default value is 1

SWMS RECORD 3-FORMAT(9I5)

1 to 5 IGRID 0

All finite-element-network data will be entered on data records

1 Finite-element-network data will be read from a data file. Additional network data may be entered on data records. The default name of the network data file is GRID.DAT 
$\underline{\text { Columns }}$ Variable Value Description

6 to 10 INITC 0 All initial-condition data will be entered on data records

1 Initial-condition data will be read from a data file. Additional initial-condition data may be entered on data records. The default name of the initial-condition data file is INIT.DAT

Note: An initial-condition data file usually will be a flow (solution-output) data file created by a previous run

11 to 15 ISOUT 0 Solution output will not be written to a data file

$\pm \quad$ Solution output will be written to a data file at the end of a steady-state run and at the end of every time step of a timedependent run. If ISOUT $>0$, data will be written in "text" form; if ISOUT $<0$, data will be written in "binary" form. The default name of the flow data file is FLOW.DAT

16 to 20 IRSRC $0 \quad$ A restart/recovery file will not be used 


\section{$\underline{\text { Columns Variable Value Description }}$}

$\pm \quad$ Intermediate results will be written to a restart/recovery file after every iteration to allow a run to be restarted from the last successful iteration if the run terminates abnormally. If IRSRC $>0$, data will be written in "text" form; if IRSRC $<0$, data will be written in "binary" form. The default name of the restart/recovery file is RSRC.DAT

21 to 25 IBCIN 0

All boundary-condition data will be entered on data records

$+\quad$ Boundary-condition data will be read from a data file. Additional boundarycondition data may be entered on data records. The default name of the boundary-condition data file is BOUN.DAT

26 to $30 \quad$ IWDIN 0

All wind data will be entered on data records

$+\quad$ Wind data will be read from a data file. Additional wind data may be entered on data records. The default name of the wind data file is WIND.DAT

31 to 35 IHDIN 0

All ground-water-head data will be entered on data records 


\begin{tabular}{|c|c|c|c|}
\hline$\underline{\text { Columns }}$ & Variable & $\begin{array}{l}\text { Value } \\
+\end{array}$ & $\begin{array}{l}\text { Description } \\
\text { Ground-water-head data will be read from } \\
\text { a data file. Additional ground-water-head } \\
\text { data may be entered on data records. The } \\
\text { default name of the ground-water-head } \\
\text { data file is HEAD.DAT }\end{array}$ \\
\hline 36 to 40 & ILCOF & + & $\begin{array}{l}\text { Unit number of the "binary" file that will } \\
\text { contain the lower triangular decompositior } \\
\text { of the coefficient matrix. The default unit } \\
\text { number is } 98 \text {. The file is written only if } \\
\text { quasi-Newton iterations are to be } \\
\text { performed or if the upper and lower } \\
\text { triangular matrices are to be saved at the } \\
\text { end of a run. The default name of the } \\
\text { lower-coefficient-matrix file is } \\
\text { LOWER.DAT }\end{array}$ \\
\hline 41 to 45 & IUCOF & + & $\begin{array}{l}\text { Unit number of the "binary" file that will } \\
\text { contain the upper triangular } \\
\text { decomposition of the coefficient matrix. } \\
\text { The default unit number is } 99 \text {. The file is } \\
\text { always written. The default name of the } \\
\text { upper-coefficient-matrix file is } \\
\text { UPPER.DAT }\end{array}$ \\
\hline
\end{tabular}

SWMS RECORD 4-FORMAT(4I10,4E10.0)

1 to 10 NITS 0 A steady-state solution will not be performed

$+\quad$ Steady-state-solution iteration code read as $K K J J I I$, where:

$I I=$ number of initial full-Newton

iterations to be performed (usually 2 or 3 ) 


\section{$\underline{\text { Columns Variable Value Description }}$}

$J J=$ number of quasi-Newton iterations to be performed after all the initial full-Newton iterations and after each additional full-Newton iteration

$K K=$ number of additional full-Newton iterations to be performed

Note: The maximum allowable number of steady-state iterations is 99 . Therefore, $I I+J J \times(1+K K)$ must be less than or equal to 99

11 to 20 NITD 0 A time-dependent solution will not be performed

$+\quad$ Time-dependent-solution iteration code read as $K K J J I I$, where $I I, J J$, and $K K$ for each time step are the same as for a steady-state solution. The maximum total number of iterations at a time step is 99

21 to $30 \quad$ NUPV $\quad 0$ to 5 Number of update vectors to be used in a quasi-Newton solution. If NUPV $=0$, no update vectors are used, and modifiedNewton iteration results. The maximum value is 5 . The default value is 0 (that is, a modified-Newton iteration is the default)

31 to 40 NITP $+\quad$ Iteration print code read as $K K J J I I$, where: 
$\underline{\text { Columns Variable Value Description }}$

$I I=$ number of iterations skipped between printed output during a steadystate solution

$J J=$ number of iterations skipped between printed output during each time step of a time-dependent solution $K K=$ number of time steps skipped between printed output during a timedependent solution

Note: The default value for $I I, J J$, and $K K$ is 0 (that is, output will be printed at the end of every iteration of both steadystate and time-dependent solutions and for every time step of a time-dependent solution)

41 to 50 TSTRT $+\quad$ Starting simulation time, in hours

51 to 60 TMAX 0 - A time-dependent solution will not be performed

$+\quad$ Maximum simulation time, in hours, for a time-dependent solution

61 to 70 DELT $+\quad$ Length, in hours, of each time step used in a time-dependent solution

71 to 80 THETA $+\quad$ Time-integration factor (dimensionless). The minimum value is 0.5 ; the maximum value is 1.0 


\section{SWMS RECORD 5-FORMAT(8E10.0)}

\begin{tabular}{|c|c|c|c|}
\hline$\underline{\text { Columns }}$ & $\underline{\text { Variable }}$ & Value & Description \\
\hline 1 to 10 & WSEL & + & $\begin{array}{l}\text { Water-surface elevation, in feet (meters), } \\
\text { assigned to each node in a network } \\
\text { that has not been assigned an initial } \\
\text { water-surface elevation. WSEL can be used } \\
\text { to assign a constant water-surface } \\
\text { elevation for a cold start }\end{array}$ \\
\hline \multirow[t]{2}{*}{11 to 20} & OMEGA & 0 & $\begin{array}{l}\text { Effect of the Coriolis force will not be } \\
\text { considered }\end{array}$ \\
\hline & & \pm & $\begin{array}{l}\text { Average local latitude, in degrees, of the } \\
\text { surface-water body being modeled. OMEGA } \\
\text { is positive in the northern hemisphere and } \\
\text { negative in the southern hemisphere }\end{array}$ \\
\hline
\end{tabular}

21 to 30 ROWAT $\quad+\quad$ Average water density, in slugs per cubic foot (kilograms per cubic meter). The default value is $1.937 \mathrm{slug} / \mathrm{ft}^{3}$ $\left(999.0 \mathrm{~kg} / \mathrm{m}^{3}\right)$

31 to 40 BETAO $+\quad$ Coefficient $\beta_{0}$ (dimensionless) in equation 4-8 (of the original users manual) used to compute the momentum-correction coefficient. The default value is is 1.0

41 to 50 CBETA $\quad+\quad$ Coefficient $c_{\beta}$ (dimensionless) in equation 4-8 (of the original users manual) used to compute the momentum-correction coefficient. The default value is 0 


\begin{tabular}{|c|c|c|c|}
\hline$\underline{\text { Columns }}$ & Variable & Value & Description \\
\hline 51 to 60 & CFLAG & + & $\begin{array}{l}\text { Continuity-norm flag value. Continuity } \\
\text { norms greater than CFLAG will be flagged } \\
\text { with an asterisk. Appropriate values are } \\
\text { problem dependent. The default value is } \\
1.0 \mathrm{E}+35 \text { (that is, continuity norms will } \\
\text { not be flagged) }\end{array}$ \\
\hline 61 to 70 & DEPTOL & + & $\begin{array}{l}\text { Depth tolerance, in feet (meters), used } \\
\text { during automatic boundary adjustment to } \\
\text { decide whether or not to turn on an } \\
\text { element. The default value is } 0.5 \mathrm{ft} \\
(0.15 \mathrm{~m})\end{array}$ \\
\hline
\end{tabular}

71 to 80 RELAX 0 to 2 Relaxation factor (dimensionless) used in equation solution $\left(\omega_{r}\right.$ in equation $7-6$ of the original users manual). The default value is 1.0

SWMS RECORD 6-FORMAT(7E10.0)

1 to 10 WVEL $\quad+\quad$ Wind velocity, in feet per second (meters per second). This value will be assigned to each node in the network unless overridden

11 to 20 WDIR $+\quad$ Wind-direction angle, in degrees, measured counterclockwise from the positive $x$-axis. This is the direction toward which the wind is blowing. This value will be assigned to each node in the network unless overridden 
$\underline{\text { Columns Variable Value Description }}$

21 to 30 ROAIR $+\quad$ Air density, in slugs per cubic foot (kilograms per cubic meter). The default value is $0.00237 \mathrm{slug} / \mathrm{ft}^{3}\left(1.225 \mathrm{~kg} / \mathrm{m}^{3}\right)$

31 to 40 CSURF1 $+\quad$ Coefficient $c_{s 1}$ (dimensionless) in equation $4-15$ of the original users manual. It is used to compute the wind-stress coefficient. The default value is 1.0

41 to 50 CSURF2 $+\quad$ Coefficient $c_{s 2}$, in seconds per meter, in equation 4-15 of the original users manual. It is used to compute the wind-stress coefficient. The default value is $0 \mathrm{~s} / \mathrm{m}$

51 to 60 WVMIN $+\quad$ Minimum wind velocity, $W_{\min }$, in meters per second, used in equation 4-15 of the original users manual. It is used to compute the wind-stress coefficient. The default value is $0 \mathrm{~m} / \mathrm{s}$

61 to 70 GWHEAD $+\quad$ Ground-water head, in feet (meters). This value will be assigned to each node in the network unless overridden 


\section{Element Data Set}

Element data records immediately follow an ELEM-data-set identification record. One record is required for each element. An element data record contains the element number, the sequence of nodes connected to the element (the element connectivity list), the turbulence-model code, the friction code, the vegetation code, the precipitation code, the evapotranspiration code, the ground-water-seepage code, and the element assembly sequence. Two options for the ELEM-record format are available (see the variable GRIDF on the SWMS identification record of the program-control data set). The second option can be used to avoid the overlapping of node numbers when node numbers exceed 10,000 . The data set is terminated with one or more blank records.

\section{ELEM IDENTIFICATION RECORD—FORMAT(A4)}

\section{$\underline{\text { Columns Variable }}$ Value Description \\ 1 to 4 IDS ELEM Element-data-set identification code}

ELEM RECORD—FORMAT((11I5,5I3,I5) or $(10 \mathrm{I} 6,15,5 \mathrm{I} 2, \mathrm{I} 5))$

1 to $5 \quad \mathrm{~L} \quad+\quad$ Element number. It must be less than or (1 to 6) equal to the element-array dimension

6 to $50 \quad \operatorname{NOP}(\mathrm{L}, \mathrm{K})+$ Element connectivity list, the sequence ( 7 to 60 ) of nodes connected to the element: six node numbers for a triangular element, eight node numbers for a serendipity quadrangular element, or nine node numbers for a Lagrangian quadrangular element. The list starts at any corner node and proceeds in a counterclockwise direction around the element. For a ninenode quadrangular element, the center node is entered last 


\begin{tabular}{|c|c|c|c|}
\hline$\underline{\text { Columns }}$ & $\underline{\text { Variable }}$ & $\underline{\text { Value }}$ & Description \\
\hline $\begin{array}{l}51 \text { to } 55 \\
(61 \text { to } 65)\end{array}$ & $\operatorname{LTRB}(\mathrm{L})$ & \pm & $\begin{array}{l}\text { Turbulence code. The code corresponds to } \\
\text { a set of turbulence-model coefficients that } \\
\text { are entered in the TURB data set. If } \\
\text { LTRB (L) }<1 \text {, the element will be turned } \\
\text { off (that is, the element will not be used in } \\
\text { computations). If LTRB (L) }>1000 \text {, } \\
\text { pressure flow will be permitted at the } \\
\text { element }\end{array}$ \\
\hline $\begin{array}{l}56 \text { to } 58 \\
(66 \text { to } 67)\end{array}$ & $\operatorname{LFRC}(\mathrm{L})$ & + & $\begin{array}{l}\text { Friction code. The code corresponds to a } \\
\text { set of friction coefficients that are entered } \\
\text { in the FRIC data set }\end{array}$ \\
\hline $\begin{array}{l}59 \text { to } 61 \\
\text { ( } 68 \text { to } 69)\end{array}$ & LVEG (L) & + & $\begin{array}{l}\text { Vegetation code. The code corresponds to } \\
\text { a set of vegetation characteristics that are } \\
\text { entered in the VEGE data set }\end{array}$ \\
\hline $\begin{array}{l}62 \text { to } 64 \\
\text { ( } 70 \text { to } 71 \text { ) }\end{array}$ & $\operatorname{LPRC}(\mathrm{L})$ & + & $\begin{array}{l}\text { Precipitation code. The code corresponds } \\
\text { to a precipitation rate that is entered in } \\
\text { the PREC data set }\end{array}$ \\
\hline $\begin{array}{l}65 \text { to } 67 \\
\text { ( } 72 \text { to } 73 \text { ) }\end{array}$ & LEVP (L) & + & $\begin{array}{l}\text { Evapotranspiration code. The code } \\
\text { corresponds to an evapotranspiration rate } \\
\text { that is entered in the EVAP data set }\end{array}$ \\
\hline $\begin{array}{l}68 \text { to } 70 \\
(74 \text { to } 75)\end{array}$ & LGWT (L) & + & $\begin{array}{l}\text { Ground-water-seepage code. The code } \\
\text { corresponds to a set of ground-water- } \\
\text { seepage parameters that are entered in the } \\
\text { GRWT data set }\end{array}$ \\
\hline
\end{tabular}


$\underline{\text { Columns Variable Value Description }}$

71 to 75 LSEQ (L) $+\quad$ Element assembly sequence. The sequence.

(76 to 80 ) number of the element for processing by the frontal method. An efficient element sequence can be generated by using the resequencing option of the preprocessing program

Terminate the ELEM data set with one or more blank records. 


\section{Node Data Set}

Node data records immediately follow a NODE-data-set identification record. The identification record contains the data-set identification code and factors used to convert node-point coordinates and ground and ceiling (Froehlich, 1989, p. 1-4-21) elevations read from data records to the desired units (either feet or meters). A node data record contains the node number, the $x$ - and $y$-coordinates of the node, and the ground-surface and ceiling elevations at the node. A node data record is required for each vertex node. Curved element sides are specified by also entering coordinate data for the midside node of the element side. Note that because bed and ceiling elevations are interpolated within an element using linear functions, values for these variables are needed only at vertex nodes. Therefore, bed and ceiling elevations specified at midside and center nodes will be ignored. The data set is terminated with one or more blank records.

\section{NODE IDENTIFICATION RECORD-FORMAT(A4,6X,6E10.0)}

\begin{tabular}{|c|c|c|c|}
\hline$\underline{\text { Columns }}$ & $\underline{\text { Variable }}$ & $\underline{\text { Value }}$ & Description \\
\hline 1 to 4 & IDS & NODE & Node-data-set identification code \\
\hline 5 to 10 & - & - & Not used \\
\hline 11 to 20 & $\mathrm{XFACT}$ & + & $\begin{array}{l}\text { Multiplication factor used to convert } \\
x \text {-coordinates read from data records to } \\
\text { feet (meters). The default value is } 1.0\end{array}$ \\
\hline 21 to 30 & YFACT & + & $\begin{array}{l}\text { Multiplication factor used to convert } \\
y \text {-coordinates read from data records to } \\
\text { feet (meters). The default value is } 1.0\end{array}$ \\
\hline 31 to 40 & $\mathrm{ZFACT}$ & + & $\begin{array}{l}\text { Multiplication factor used to convert } \\
\text { ground and ceiling elevations read from } \\
\text { data records to feet (meters). The default } \\
\text { value is } 1.0\end{array}$ \\
\hline
\end{tabular}




\begin{tabular}{|c|c|c|c|}
\hline$\underline{\text { Columns }}$ & $\underline{\text { Variable }}$ & $\underline{\text { Value }}$ & Description \\
\hline 41 to 50 & XZERO & + & $\begin{array}{l}\text { Feet (meters) to be added to all } x \text { - } \\
\text { coordinates read from data records after } \\
\text { multiplication by XFACT. The default } \\
\text { value is } 0 \mathrm{ft}(\mathrm{m})\end{array}$ \\
\hline 51 to 60 & YZERO & + & $\begin{array}{l}\text { Feet (meters) to be added to all } y \text { - } \\
\text { coordinates read from data records after } \\
\text { multiplication by YFACT. The default } \\
\text { value is } 0 \mathrm{ft}(\mathrm{m})\end{array}$ \\
\hline 61 to 70 & ZZERO & + & $\begin{array}{l}\text { Feet (meters) to be added to all ground } \\
\text { and ceiling elevations read from data } \\
\text { records after multiplication by ZFACT. } \\
\text { The default value is } 0 \mathrm{ft}(\mathrm{m})\end{array}$ \\
\hline \multicolumn{4}{|c|}{ NODE RECORD—FORMAT(I10,4E10.0) } \\
\hline 1 to 10 & $\mathrm{~N}$ & + & $\begin{array}{l}\text { Node number. It must be less than or } \\
\text { equal to the node-array dimension }\end{array}$ \\
\hline 11 to 20 & $\operatorname{CORD}(N, 1)$ & + & The $x$-coordinate of node $\mathrm{N}$ \\
\hline 21 to 30 & $\operatorname{CORD}(N, 2)$ & + & The $y$-coordinate of node $\mathrm{N}$ \\
\hline 31 to 40 & $\operatorname{GRND}(N)$ & + & Ground-surface elevation at node $\mathbf{N}$ \\
\hline 41 to 50 & $\operatorname{CEIL}(\mathrm{N})$ & + & Ceiling elevation at node $\mathrm{N}$ \\
\hline & & & $\begin{array}{l}\text { Note: Coordinates and elevations are } \\
\text { converted to feet (meters) by the factors } \\
\text { specified on the data-set identification } \\
\text { record. Therefore, any system of units } \\
\text { can be used to record coordinates and } \\
\text { elevations }\end{array}$ \\
\hline
\end{tabular}

Terminate the NODE data set with one or more blank records. 


\section{Turbulence-Model Data Set}

Turbulence-model data records immediately follow a TURB-data-set identification record. One record is required for each set of turbulence-model coefficients. The coefficients in this record are applied to all elements that have been assigned the turbulence code of the record. The data set is terminated with one or more blank records.

TURB IDENTIFICATION RECORD_FORMAT(A4)

$\underline{\text { Columns Variable Value Description }}$

1 to 4 IDS TURB Turbulence-model-data-set identification code

TURB RECORD-FORMAT(I10,2E10.0)

1 to $10 \quad \mathrm{M} \quad+\quad$ Turbulence code

Note: Elements can be effectively removed from the network by assigning the turbulence-model code a negative value. All elements having the negative code will be "turned off" during the computations

Note: Pressure flow will be permitted at elements assigned a code greater than 1,000

11 to $20 \operatorname{PTRB}(\mathrm{M}, 1)+\quad$ Turbulence-model base kinematic eddy viscosity, $\hat{\nu}_{0}$, in square feet per second (square meters per second), used in equation 4-19 of the original users manual

21 to $30 \operatorname{PTRB}(\mathrm{M}, 2)+\quad$ Turbulence-model coefficient, $c_{\mu}$ (dimensionless), used in equation 4-19 of the original users manual

Terminate the TURB data set with one or more blank records. 


\section{Friction Data Set}

Friction data records immediately follow a FRIC-data-set identificatior record. One record is required for each set of friction coefficients. A frictior data record contains a friction code, a Manning roughness coefficient as $\hat{c}$. function of depth, a Chézy discharge coefficient, and a linear friction coefficient. The coefficients in this record are applied to all elements that have been assigned the friction code of the record. The data set is terminatec' with one or more blank records.

\section{FRIC IDENTIFICATION RECORD-FORMAT(A4)}

Columns Variable Value Description

1 to 4 IDS FRIC Friction-data-set identification code

FRIC RECORD-FORMAT(I10,6E10.0)

1 to $10 \quad \mathrm{M}+\quad$ Friction code

11 to $20 \operatorname{PFRC}(\mathrm{M}, 1)+\quad$ Manning roughness coefficient applied to all water depths less than or equal to the depth entered in the next field

21 to $30 \operatorname{PFRC}(\mathrm{M}, 2)+$ Water depth, in feet (meters), below which the roughness coefficient entered in the previous field is applied

31 to $40 \operatorname{PFRC}(M, 3)+$ Manning roughness coefficient applied to all water depths greater than or equal to the depth entered in the next field

41 to $50 \operatorname{PFRC}(M, 4)+$ Water depth, in feet (meters), above which the roughness coefficient entered in the previous field is applied 
$\underline{\text { Columns Variable Value Description }}$

Note: For depths greater than the first depth and less than the second depth entered above, the roughness coefficient is linearly interpolated. If the second coefficient is zero or blank, the first coefficient is applied to all depths

51 to $60 \quad \operatorname{PFRC}(M, 5)+$

Chézy discharge coefficient (dimensionless) used for all water depths. This coefficient is multipled by the square root of gravitational acceleration to obtain the dimensional value used in calculations

61 to $70 \operatorname{PFRC}(M, 6)+\quad$ Coefficient of linear friction, in seconds per foot (seconds per meter), used in equation 4.3

Terminate the FRIC data set with one or more blank records. 


\section{Wind Data Set}

An optional wind data set, identified as WIND, is used if wind is to be modeled. Wind data records immediately follow a WIND-data-set identification record. One record is required for each node at which conditions other than general wind specifications are desired. For a time-dependent (unsteady) run, only values that change from the previous time step need to be specified. A wind data record contains the node number and the specified wind velocity and direction. The data set is terminated with one or more blank records.

\section{WIND IDENTIFICATION RECORD-FORMAT(A4)}

$\underline{\text { Columns Variable Value Description }}$

1 to 4 IDS WIND Wind-data-set identification code

WIND RECORD—FORMAT(I10,2E10.0)

1 to $10 \quad \mathrm{~N} \quad+\quad$ Node number. It must be less than or equal to the node-array dimension

11 to 20 SIGMA $(\mathrm{N}, 1)+\quad$ Wind velocity, in feet per second (meters per second), at node $\mathrm{N}$

21 to $30 \operatorname{SIgMA}(\mathrm{N}, 2)+$ Wind direction, in degrees measured counterclockwise from the positive $x$-direction, at node $\mathrm{N}$. This is the direction toward which the wind is blowing

Terminate the WIND data set with one or more blank records. 


\section{Vegetation Data Set}

An optional vegetation data set, identified as VEGE, is used if vegetative sheltering of the water surface from wind is to be modeled. Vegetatior data records immediately follow a VEGE-data-set identification record. One record is required for each set of vegetation parameters. A vegetation data. record contains a vegetation code, a vegetation density, an average stem or leaf width and height, and a vegetation drag coefficient. The coefficients ir this record are applied to all elements that have been assigned the vegetation code of the record. The data set is terminated with one or more blank records.

\section{VEGE IDENTIFICATION RECORD-FORMAT(A4)}

$\underline{\text { Columns Variable Value Description }}$

1 to 4 IDS VEGE Vegetation-data-set identification code

VEGE RECORD-FORMAT(I5,4E10.0)

1 to $10 \quad \mathrm{M} \quad+\quad$ Vegetation code

11 to 20 PVEG $(\mathrm{M}, 1)+\quad$ Plant density, in stems or leaves per square foot (stems or leaves per square meter)

21 to 30 PVEG $(M, 2)+\quad$ Average stem or leaf width, in feet (meters)

31 to 40 PVEG $(M, 3)+$ Average stem or leaf height, in feet (meters)

41 to $50 \operatorname{PVEG}(\mathrm{M}, 4)+\quad$ Vegetation drag coefficient (dimensionless)

Terminate the VEGE data set with one or more blank records. 


\section{Precipitation Data Set}

An optional precipitation data set, identified as PREC, is used if precipitation is to be modeled. Precipitation data records immediately follow a PREC-data-set identification record. One record is required for each precipitation code. A precipitation data record contains a precipitation code and a precipitation rate. The precipitation rate in this record is applied to all elements that have been assigned the precipitation code of the record. The data set is terminated with one or more blank records.

\section{PREC IDENTIFICATION RECORD-FORMAT(A4)}

\section{$\underline{\text { Columns Variable Value } \text { Description }}$}

1 to 4 IDS PREC Precipitation-data-set identification code

$$
\text { PREC RECORD - FORMAT(I10,E10.0) }
$$

1 to $10 \quad \mathrm{M} \quad+\quad$ Precipitation code

11 to 20 PPRC (M) $+\quad$ Precipitation rate, in inches per hour (centimeters per hour)

Terminate the PREC data set with one or more blank records. 


\section{Evapotranspiration Data Set}

An optional evapotranspiration data set, identified as EVAP, is used if evapotranspiration is to be modeled. Evapotranspiration data records immediately follow an EVAP-data-set identification record. One record is required for each evapotranspiration code. An evapotranspiration data record contains an evapotranspiration code and an evapotranspiration rate. The evapotranspiration rate in this record is applied to all elements that have been assigned the evapotranspiration code of the record. The data set is terminated with one or more blank records.

\section{EVAP IDENTIFICATION RECORD-FORMAT(A4)}

\begin{tabular}{|c|c|c|c|}
\hline$\underline{\text { Columns }}$ & $\underline{\text { Variable }}$ & $\underline{\text { Value }}$ & Description \\
\hline 1 to 4 & IDS & EVAP & $\begin{array}{l}\text { Evapotranspiration-data-set identification } \\
\text { code }\end{array}$ \\
\hline \multicolumn{4}{|c|}{ EVAP RECORD-FORMAT(I10,E10.0) } \\
\hline 1 to 10 & M & + & Evapotranspiration code \\
\hline 11 to 20 & $\operatorname{PEVP}(M)$ & + & $\begin{array}{l}\text { Evapotranspiration rate, in inches per day } \\
\text { (centimeters per day) }\end{array}$ \\
\hline
\end{tabular}

Terminate the EVAP data set with one or more blank records. 


\section{Ground-Water-Seepage Data Set}

An optional ground-water-seepage data set, identified as GRWT, is used if ground-water seepage is to be modeled. Ground-water-seepage data records immediately follow a GRWT-data-set identification record. One record is required for each set of ground-water-seepage parameters. A ground-waterseepage data record contains a ground-water-seepage code, a conductance. and the thickness of the low-permeability layer. The parameters in this record are applied to all elements that have been assigned the ground-water-seepage code of the record. The data set is terminated with one or more blank records.

\section{GRWT IDENTIFICATION RECORD-FORMAT(A4)}

\section{$\underline{\text { Columns }}$ Variable Value Description}

1 to 4 IDS GRWT Ground-water-seepage-data-set identification code

GRWT RECORD-FORMAT(I10,2E10.0)

1 to $10 \quad M \quad+\quad$ Ground-water-seepage code

11 to 20 PGWT $(M, 1)+\quad$ Conductance, per second

21 to 30 PGWT $(M, 2)+$ Thickness of the low-permeability layer below the bed, in feet (meters)

Terminate the GRWT data set with one or more blank records. 


\section{Ground-Water-Head Data Set}

An optional ground-water-head data set, identified as HEAD, is used if ground-water seepage is to be modeled. Ground-water-head data records immediately follow a HEAD-data-set identification record. One record is required for each node at which a ground-water head other than the ground-water head given in SWMS record 6 is desired. For a time-dependent (unsteady) run, only values that change from the previous time step need to be specified. A ground-water-head data record contains the node number and the ground-water head. Values entered on data records will override those read from a ground-water-head data file. The data set is terminated with one or more blank records.

\section{HEAD IDENTIFICATION RECORD-FORMAT(A4)}

$\begin{array}{llll}\text { Columns } & \text { Variable } & \text { Value } & \text { Description } \\ 1 \text { to } 4 & \text { IDS } & \text { HEAD } & \begin{array}{l}\text { Ground-water-head-data-set identification } \\ \text { code }\end{array} \\ & & \text { HEAD RECORD-FORMAT(I10,E10.0) }\end{array}$

Terminate the HEAD data set with one or more blank records. 


\section{Initial-Condition Data Set}

Initial-condition data records immediately follow an INIT-data-set identification record. One record is prepared for each node at which initial conditions are specified. An initial-condition data record contains the node number, the initial velocities in the $x$ - and $y$-directions, the depth of flow, and time derivatives of the $x$ - and $y$-velocities and the depth of flow. Values entered on data records will override those read from an initial-condition data file. Two options for the INIT-record format are available (see the variable FLOWF on the SWMS identification record of the program-control data set). The second option can be used to retain additional significant digits. The data set is terminated with one or more blank records.

\section{INIT IDENTIFICATION RECORD-FORMAT(A4)}

$\begin{array}{llll}\text { Columns } & \text { Variable } & \text { Value } & \text { Description } \\ 1 \text { to } 4 & \text { IDS } & \text { INIT } & \begin{array}{l}\text { Initial-condition-data-set identification } \\ \text { code }\end{array}\end{array}$

INIT RECORD-FORMAT((I10,6E10.0) or (I7,6E12.5))

\begin{tabular}{|c|c|c|c|}
\hline $\begin{array}{l}1 \text { to } 10 \\
(1 \text { to } 7)\end{array}$ & $N$ & + & $\begin{array}{l}\text { Node number. It must be less than or } \\
\text { equal to the node-array dimension }\end{array}$ \\
\hline $\begin{array}{l}11 \text { to } 20 \\
(8 \text { to } 19)\end{array}$ & $\operatorname{VEL}(1, N)$ & + & $\begin{array}{l}\text { Initial } x \text {-velocity, in feet per second } \\
\text { (meters per second), at node } \mathrm{N}\end{array}$ \\
\hline $\begin{array}{l}21 \text { to } 30 \\
(20 \text { to } 31)\end{array}$ & $\operatorname{VEL}(2, N)$ & + & $\begin{array}{l}\text { Initial } y \text {-velocity, in feet per second } \\
\text { (meters per second), at node } \mathbb{N}\end{array}$ \\
\hline $\begin{array}{l}31 \text { to } 40 \\
\text { (32 to } 43)\end{array}$ & $\operatorname{VEL}(3, N)$ & + & $\begin{array}{l}\text { Initial depth of flow, in feet (meters), at } \\
\text { node } \mathbf{N}\end{array}$ \\
\hline $\begin{array}{l}41 \text { to } 50 \\
(44 \text { to } 55)\end{array}$ & $\operatorname{VDOT}(1, N)$ & + & $\begin{array}{l}\text { Initial } x \text {-velocity time rate of change, in } \\
\text { feet per second per second (meters per } \\
\text { second per second), at node } N\end{array}$ \\
\hline
\end{tabular}


$\underline{\text { Columns }}$ Variable Value Description

51 to 60 VDOT $(2, N)+\quad$ Initial $y$-velocity time rate of change, in (56 to 67) feet per second per second (meters per second per second), at node $\mathrm{N}$

61 to $70 \operatorname{VDOT}(3, \mathrm{~N})+\quad$ Initial flow-depth time rate of change, in (68 to 79$)$ feet per second (meters per second), at node $\mathbf{N}$

Terminate the INIT data set with one or more blank records. 


\section{Boundary-Condition Data Set}

Boundary-condition data records immediately follow a BOUN-data-set identification record. One record is prepared for each boundary node at which conditions other than slip/no-slip are specified. For a time-dependent (unsteady) run, only values that change from the previous time step need to be specified. A boundary-condition data record contains the number of the node to which the data apply, a boundary-condition code, and specified conditions. Either tangential-flow (slip) or zero-flow (no-slip) conditions (as specified by the variable ISLIP on SWMS data record 2) are applied automatically at all boundary nodes unless otherwise specified. Values entered on data records will override those read from a boundary-condition data file. The data set is terminated with one or more blank records.

\section{BOUN IDENTIFICATION RECORD-FORMAT(A4)}

$\begin{array}{llll}\text { Columns } & \text { Variable } & \text { Value } & \text { Description } \\ 1 \text { to } 4 & \text { IDS } & \text { BOUN } & \begin{array}{l}\text { Boundary-condition-data-set identification } \\ \text { code }\end{array}\end{array}$
BOUN RECORD-FORMAT(I10,5X,I5,3E10.0)

1 to $10 \quad \mathrm{~N} \quad+\quad$ Node number. It must be less than or equal to the node-array dimension

11 to $15-\quad \quad-\quad$ Not used

16

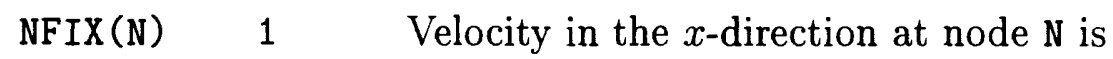
specified

2 Unit flow in the $x$-direction at node $\mathrm{N}$ is specified

3 Velocity tangent to the boundary at node $\mathrm{N}$ is specified 
$\underline{\text { Columns Variable Value Description }}$

$4 \quad$ Unit flow tangent to the boundary at node $\mathrm{N}$ is specified

$5 \quad$ Total flow normal to the open boundary resulting from flow at node $\mathbf{N}$ is specified

17

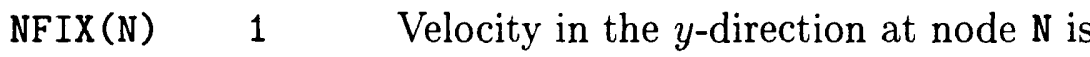
specified

2 Unit flow in the $y$-direction at node $\mathrm{N}$ is specified

3 Velocity normal to the boundary at node $\mathbf{N}$ is specified

$4 \quad$ Unit flow normal to the boundary at node $\mathrm{N}$ is specified

5 Total flow normal to the closed boundary resulting from flow at node $\mathrm{N}$ is specified

Note 1: A zero-flow (no-slip) condition is applied at a boundary node by entering a " 1 " in columns 16 and 17 and specifying the $x$ - and $y$-velocities to be zero. A tangential-flow (slip) condition is applied at a boundary node by entering a " 0 " in column 16, a " 5 " in column 17 and specifying the total flow normal to the boundary to be zero 


\section{$\underline{\text { Columns Variable Value }}$ Description}

Note 2: Special consideration must be given nodes where closed and open boundaries meet. Prescribed unit flow or velocity must be parallel to the closed boundary at these nodes. If the water-surface elevation is prescribed, tangential or zero flow must be specified as described in Note 1 above

18

$\operatorname{NFIX(N)} \quad 1$

Water-surface elevation at node $\mathrm{N}$ is specified as an essential boundary condition

2 Water-surface elevation at node $\mathrm{N}$ is specified as a natural boundary condition

$3 \quad$ Supercritical flow exists at the outflow boundary node. Water-surface elevation is not specified

19

NFIX (N) - $\quad$ Not used. Enter zero

20
$\operatorname{NFIX(N)}$
Not used. Enter zero

21 to $30 \quad \operatorname{SPEC}(\mathrm{N}, 1)+$

Specified velocity, in feet per second (meters per second), or unit flow, in square feet per second (square meters per second), in the $x$-direction or tangent to the boundary at node $\mathrm{N}$ 
Columns Variable Value Description

31 to $40 \operatorname{SPEC}(\mathrm{N}, 2)+\quad$ Specified velocity, in feet per second (meters per second), or unit flow, in square feet per second (square meters per second), in the $y$-direction or normal to the boundary at node $\mathrm{N}$; or total flow, in cubic feet per second (cubic meters per second), normal to the boundary at node $\mathrm{N}$

Note: If total flow is specified, a positive value indicates flow into a network and a negative value indicates flow out of a network resulting from flow at node $\mathrm{N}$

41 to $50 \operatorname{SPEC}(\mathrm{N}, 3)+$ Specified water-surface elevation, in feet (meters), at node $\mathrm{N}$

Terminate the BOUN data set with one or more blank records. 


\section{Total-Flow-Cross-Section Data Set}

Total-flow-cross-section data records immediately follow a QSEC-data-set identification record. A set of records is required for each section of the open boundary of a network for which a total flow will be specified. For each cross section, the first record contains a cross-section identification number and the total flow. A list of the nodes that define the cross section is contained on up to five additional records. A maximum of 10 cross sections may bo specified. The data set is terminated with one or more blank records.

\section{QSEC IDENTIFICATION RECORD-FORMAT(A4)}

\begin{tabular}{|c|c|c|c|}
\hline$\underline{\text { Columns }}$ & $\underline{\text { Variable }}$ & $\underline{\text { Value }}$ & Description \\
\hline 1 to 4 & IDS & QSEC & $\begin{array}{l}\text { Total-flow-cross-section-data-set } \\
\text { identification code }\end{array}$ \\
\hline \multicolumn{4}{|c|}{ QSEC RECORD 1-FORMAT(I10,E10.0) } \\
\hline 1 to 10 & IXSQ & 1 to 10 & Cross-section identification number \\
\hline 11 to 20 & $\mathrm{XSQ}(\mathrm{IXSQ})$ & \pm & $\begin{array}{l}\text { Total flow, in cubic feet per second (cubic } \\
\text { meters per second), normal to the cross } \\
\text { section, to be distributed among the node } \\
\text { points that define the cross section. A } \\
\text { positive value denotes inflow }\end{array}$ \\
\hline
\end{tabular}


QSEC RECORD 2-FORMAT(16I5)

\begin{tabular}{|c|c|c|c|}
\hline$\underline{\text { Columns }}$ & Variable & $\underline{\text { Value }}$ & Description \\
\hline 1 to 80 & LXSQN (K) & + & $\begin{array}{l}\text { List of node numbers that define a } \\
\text { connected series of element sides of the } \\
\text { network boundary that is open (that is, } \\
\text { through which flow can enter or leave the } \\
\text { the network). The list is terminated by a } \\
\text { "-1" entry. Up to five records ( } 79 \text { node } \\
\text { points plus the "-1" entry) may be used } \\
\text { to define a cross section. The first entry } \\
\text { for each record must be placed in the first } \\
\text { field }\end{array}$ \\
\hline & & & $\begin{array}{l}\text { Note: During a time-dependent simulation } \\
\text { total flow is not changed until a new QSEC } \\
\text { data set is read. Nodes that define the } \\
\text { cross section can be changed at any time } \\
\text { during a time-dependent run by entering a } \\
\text { new list of nodes. If no nodes change, } \\
\text { enter a "-1" in the first field }\end{array}$ \\
\hline
\end{tabular}

Terminate the QSEC data set with one or more blank records. 


\section{Water-Surface-Elevation-Cross-Section Data Set}

Water-surface-elevation-cross-section data records immediately follow a ZSEC-data-set identification record. A set of records is required for each section of the open boundary of a network for which the water-surface elevation will be specified. For each cross section, the first record contains a cross-section identification number and the water-surface elevation. A list of the nodes that define the cross section is contained on up to five additional records. A maximum of 10 cross sections may be specified. The data set is terminated with one or more blank records.

\section{ZSEC IDENTIFICATION RECORD-FORMAT(A4)}

\section{$\underline{\text { Columns Variable Value Description }}$ \\ 1 to 4 IDS ZSEC Water-surface-elevation-cross-section-data- set identification code}

\section{ZSEC RECORD 1-FORMAT(I10,2E10.0,I10)}

1 to 10 IXSZ 1 to 10 Cross-section identification number

11 to 20 XSZ1(IXSZ) $\pm \quad$ Water-surface elevation, in feet (meters), at every node in the cross section if $\mathrm{XSZ2}=0$; or water-surface elevation in feet (meters), at the first point of the cross section if $\mathrm{XSZ2} \neq 0$

21 to 30 XSZ2(IXSZ) $\pm \quad$ Water-surface elevation, in feet (meters), at the last node in the cross section if the water surface slopes from one end of the cross section to the other. Enter "0" or leave blank if the water-surface elevation is constant across the cross section 


\section{$\underline{\text { Columns Variable Value Description }}$}

\section{1 to 40 IBCZ(IXSZ) 1}

Note: If $\mathrm{XSZ2} \neq 0$, the water-surface elevation at nodes between the two end nodes is linearly interpolated between the two end nodes

Water-surface elevation will be specified as an essential boundary condition at each node of the cross section

$2 \quad$ Water-surface elevation will be specified as a natural boundary condition at each node of the cross section

3 Supercritical flow exists at each node of the cross section. The cross section is assumed to form an outflow boundary, and the water-surface elevation is not specified

\section{ZSEC RECORD 2-FORMAT(16I5)}

List of node numbers that define a connected series of element sides of the network boundary that is open (that is, through which flow can enter or leave the the network). The list is terminated by a "- 1 " entry. Up to five records (79 node points plus the " -1 " entry) may be used to define a cross section. The first entry for each record must be placed in the first field 
$\underline{\text { Columns Variable Value Description }}$

Note: During a time-dependent simulation, the water-surface elevation is not changed until a new ZSEC data set is read. Node points that define the cross section can be changed at any time during a timedependent run by entering a new list of nodes. If no nodes change, enter a " -1 " in the first field

Terminate the ZSEC data set with one or more blank records. 


\section{Weir Data Set}

Weir data records immediately follow a WEIR-data-set identification record. One record is required for each weir segment. A weir data record contains the numbers of the nodes on the upstream and downstream sides of the weir segment, the water-surface elevation outside the network if only one side of the weir is part of the network, a discharge coefficient, and the length and crest elevation of the weir segment. The data set is terminated with one or more blank records.

\section{WEIR IDENTIFICATION RECORD-FORMAT(A4)}

$\begin{array}{llll}\text { Columns } & \text { Variable } & \text { Value } & \text { Description } \\ 1 \text { to } 4 & \text { IDS } & \text { WEIR } & \text { Weir-data-set identification code }\end{array}$

WEIR RECORD-FORMAT(2I5,3E10.0)

1 to $5 \quad$ NOPW $(\mathrm{J}, 1)+\quad$ Number of the boundary node on one side of the weir segment

6 to $10 \operatorname{NOPW}(\mathrm{J}, 2) \quad 0 \quad$ Water is allowed to leave the network at the previously specified node

$+\quad$ Number of the boundary node on the opposite side of the weir segment

11 to 20 WWS2 $(\mathrm{J})+$ Water-surface elevation outside the network, in feet (meters), used if $\operatorname{NOPW}(\mathrm{J}, 2)=0$

21 to $30 \mathrm{WCOF}(\mathrm{J})+$ Discharge coefficient (dimensionless) for free-flow conditions at the weir segment $\left(C_{w}\right.$ in equation $\left.4-21\right)$, usually about 0.53

31 to 40 WLEN $(\mathrm{J})+$ Length of the weir segment $\left(L_{w}\right.$ in equation 4-21), in feet (meters) 
Columns Variable Value Description

41 to 50 WCEL $(\mathrm{J})+\quad$ Crest elevation of the weir segment $\left(z_{c}\right.$ in equation 4-20), in feet (meters)

Terminate the WEIR data set with one or more blank records. 


\section{Culvert Data Set}

Culvert data records immediately follow a CULV-data-set identification record. One record is required for each culvert. A culvert data record contains the numbers of the nodes at the upstream and downstream ends of the culvert, a discharge coefficient, and the cross-section area, hydraulic radius, length, roughness coefficient, and entrance invert elevation of the culvert. The data set is terminated with one or more blank records.

\section{CULV IDENTIFICATION RECORD-FORMAT(A4)}

$\begin{array}{llll}\text { Columns } & \text { Variable } & \text { Value } & \text { Description } \\ 1 \text { to } 4 & \text { IDS } & \text { CULV } & \text { Culvert-data-set identification code } \\ & & \text { CULV RECORD_-FORMAT }(2 I 5,6 \text { E10.0) }\end{array}$

1 to $5 \quad \operatorname{NOPC}(\mathrm{J}, 1)+\quad$ Number of the boundary node on one side of the culvert. If the node number is negative, water will only be allowed to leave the network at this node, as if a flap-gate were installed at the other end of the culvert

6 to $10 \operatorname{NOPC}(\mathrm{J}, 2) \quad 0 \quad$ Water is allowed to leave the network at the previously specified node

$+\quad$ Number of the boundary node at the other end of the culvert

11 to $20 \operatorname{CCOF}(\mathrm{J})+$ Discharge coefficient (dimensionless) for the culvert $\left(C_{c}\right.$ in equation $4-23$ or equation 4-24)

21 to $30 \operatorname{CARE}(\mathrm{J})+$ Cross-section area of the culvert $\left(A_{c}\right.$ in equation $4-23$ or equation $4-24)$, in square feet (square meters) 
$\underline{\text { Columns Variable Value Description }}$

31 to 40 CHYR(J) $+\quad$ Hydraulic radius of the culvert $\left(R_{c}\right.$ in equation $4-23$ ), in feet (meters)

41 to $50 \operatorname{CLEN}(\mathrm{J})+\quad$ Barrel length of the culvert $\left(L_{c}\right.$ in equation 4-23), in feet (meters)

51 to 60 CMAN $(\mathrm{J})+$ Manning roughness coefficient of the culvert $\left(n_{c}\right.$ in equation $\left.4-23\right)$

61 to $70 \operatorname{CELV}(\mathrm{J}) \quad 0 \quad$ Type 4 flow is assumed

$+\quad$ Entrance invert elevation of the culvert $\left(z_{\text {inv }}\right.$ in equation $\left.4-22\right)$, in feet (meters). Type 5 flow is assumed

Terminate the CULV data set with one or more blank records. 


\section{Levee Data Set}

Levee data records immediately follow a LEVE-data-set identification record. One record is required for each levee segment. A levee data record contains the numbers of the nodes on the upstream and downstream sides of the levee segment, the water-surface elevation outside the network if only on $€$ side of the levee is part of the network, the base width, top width, height, and length of the levee segment, the thickness of the subsurface layer, and the permeabilities of the levee segment and the subsurface layer. The data set is terminated with one or more blank records.

\section{LEVE IDENTIFICATION RECORD-FORMAT(A4)}

\section{$\underline{\text { Columns Variable Value Description }}$ \\ 1 to 4 IDS LEVE Levee-data-set identification code}

LEVE RECORD-FORMAT(2I6,6E7.0,2E10.3)

1 to 6 NOPL $(J, 1)+\quad$ Number of the boundary node on one side of the levee segment

7 to $12 \operatorname{NOPL}(\mathrm{J}, 2) \quad 0 \quad$ Water is allowed to enter or leave the network at the previously specified node

$+\quad$ Number of the boundary node on the other side of the levee segment

13 to 19 XLWS2 $(\mathrm{J})+$ Water-surface elevation outside the network, in feet (meters), used if $\operatorname{NOPL}(\mathrm{J}, 2)=0$

20 to $26 \operatorname{XLBAS}(\mathrm{J})+$ Base width of the levee segment $\left(b_{2}\right.$ in equation 4.11 ), in feet (meters)

27 to $33 \operatorname{XLTOP}(\mathrm{J})+\quad$ Top width of the levee segment $\left(b_{1}\right.$ in equation 4.11 ), in feet (meters) 
$\underline{\text { Columns Variable } \text { Value Description }}$

34 to $40 \operatorname{XLHGT}(\mathrm{J})+$ Height of the levee segment $\left(h_{l}\right.$ in equation 4.11), in feet (meters)

41 to $47 \operatorname{XLLEN}(\mathrm{J})+\quad$ Length of the levee segment $\left(L_{l}\right.$ in equation 5.4), in feet (meters)

48 to 54 XLTHK $(\mathrm{J})+$ Thickness of the levee-segment sublayer ( $D$ in equation 4.14), in feet (meters)

55 to 64 XLPRL $(\mathrm{J})+$ Permeability of the levee segment $\left(k_{t}\right.$ in equation 4.13), in feet per second (meters per second)

65 to 74 XLPRS $(J)+\quad$ Permeability of the levee-segment sublayer $\left(k_{u}\right.$ in equation 4.14$)$, in feet per second (meters per second)

Terminate the LEVE data set with one or more blank records. 


\section{Flux-Line Data Set}

Flux-line data records immediately follow a FLUX-data-set identification record. A flux-line data record contains node numbers that define a line of element sides across which total flow is to be computed. Flow across the first line is used as a base flow to which other calculated flows are compared. A flux line may be composed of both straight and curved element sides. The data set is terminated with one or more blank records.

\section{FLUX IDENTIFICATION RECORD-FORMAT(A4)}

$\underline{\text { Columns Variable Value Description }}$

1 to 4 IDS FLUX Flux-data-set identification code

FLUX RECORD-FORMAT(16I5)

1 to 80 LFLUXN $(K)+$ List of node numbers that define a connected series of straight or curved element sides across which total flow is to be computed. The line is terminated by a " -1 ". The first entry for each line must be placed in the first field. Use as many records as necessary to complete the line

Note: The only limit placed on the number of flux lines and the number of points that define a single line is that the total number of points in all lines may not exceed the flux-line-array dimension

Terminate the FLUX data set with one or more blank records. 


\section{Time-Dependent Data Set}

The time-dependent data record immediately follows a TIME-data-set identification record. A time-dependent data set immediately precedes sets of turbulence-model, friction, wind, vegetation, precipitation, evapotranspiration, ground-water-seepage, ground-water-head, boundary-condition, totalflow-cross-section, water-surface-elevation-cross-section, and levee data used in time-dependent (unsteady) simulations. A time-dependent data record contains the simulation time in hours at which the following data become effective and wind and ground-water-head data that apply to all nodes in the network. Time-dependent data sets and their associated turbulence-model, friction, wind, vegetation, precipitation, evapotranspiration, ground-waterseepage, ground-water-head, boundary-condition, total-flow-cross-section, water-surface-elevation-cross-section, and levee data sets must appear in chronological order at the end of the input data stream.

\section{TIME IDENTIFICATION RECORD—FORMAT(A4)}

$\begin{array}{llll}\text { Columns } & \text { Variable } & \text { Value } & \text { Description } \\ 1 \text { to } 4 & \text { IDS } & \text { TIME } & \begin{array}{l}\text { Time-dependent-data-set identification } \\ \text { code }\end{array}\end{array}$

TIME RECORD—FORMAT(5E10.0)

1 to 10 TSNEW $+\quad$ Simulation time, in hours, at which the following turbulence-model, friction, wind, vegetation, precipitation, evapotranspiration, ground-water-seepage, ground-water-head, boundary-condition, total-flow-cross-section, water-surfaceelevation-cross-section, and levee data become effective

11 to 20 WVEL $\quad+\quad$ Wind velocity, in feet (meters) per second. This value will be assigned to each node in the network unless overridden 
$\underline{\text { Columns Variable Value Description }}$

21 to 30 WDIR $+\quad$ Wind-direction angle, in degrees, measured counterclockwise from the positive $x$-axis. This value will be assigned to each node in the network unless overridden

31 to 40 ROAIR $+\quad$ Air density, in slugs per cubic foot (kilograms per cubic meter). The default value is $0.00237 \mathrm{slug} / \mathrm{ft}^{3}\left(1.225 \mathrm{~kg} / \mathrm{m}^{3}\right)$

41 to 50 GWHEAD $+\quad$ Ground-water head, in feet (meters). This value will be assigned to each node in the network unless overridden 


\section{Input Data Files}

Input data files that contain finite-element-network data, wind data. ground-water-head data, initial-condition (flow) data, and boundary-condition data can be read by FESWMS-2DH programs. Input data files may bo either formatted or unformatted. Examples of FORTRAN statements that can be used to read the data files are presented in this subsection.

\section{Network Data File}

A network data file contains node, element, and property-code data that define a finite-element network. An unformatted network data file can be read using the following FORTRAN statements:

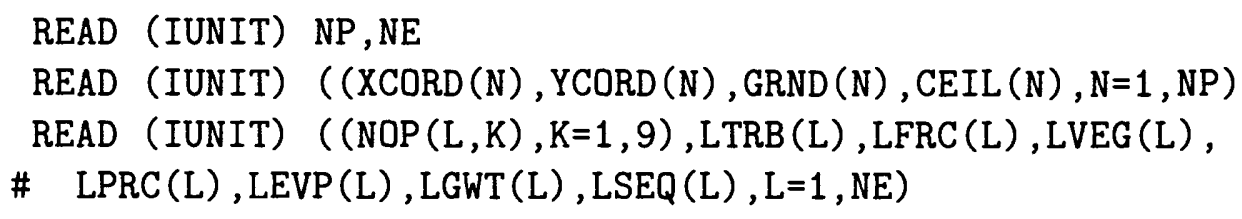

A formatted network data file can be read using the following FORTRAN statements:

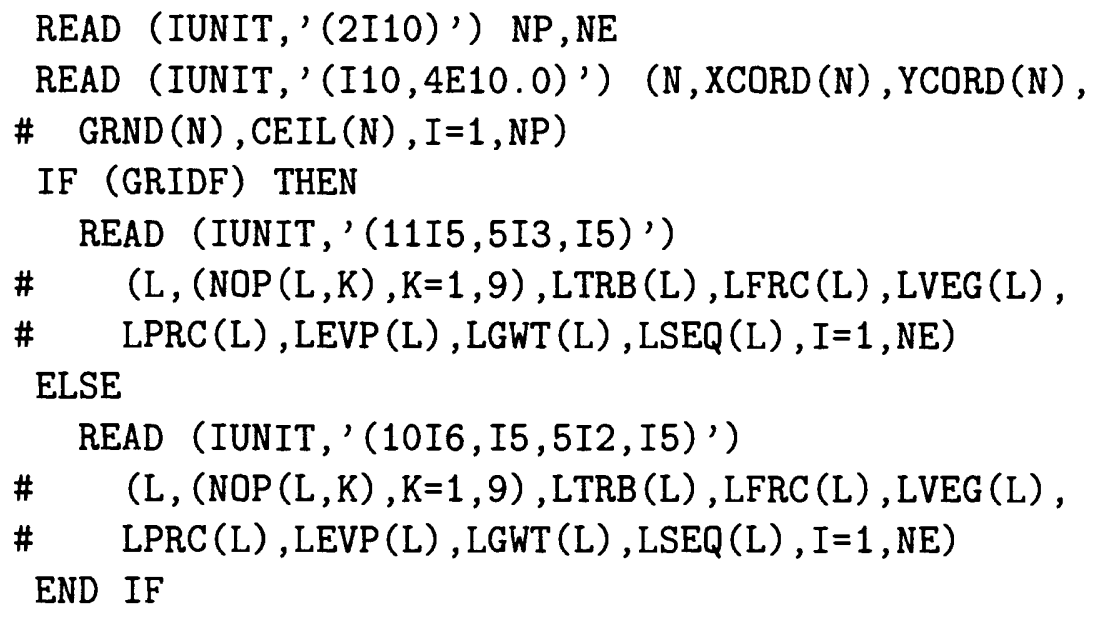

Variables contained in the preceding FORTRAN statements are defined below:

IUNIT $=$ FORTRAN unit number of the network data file, 


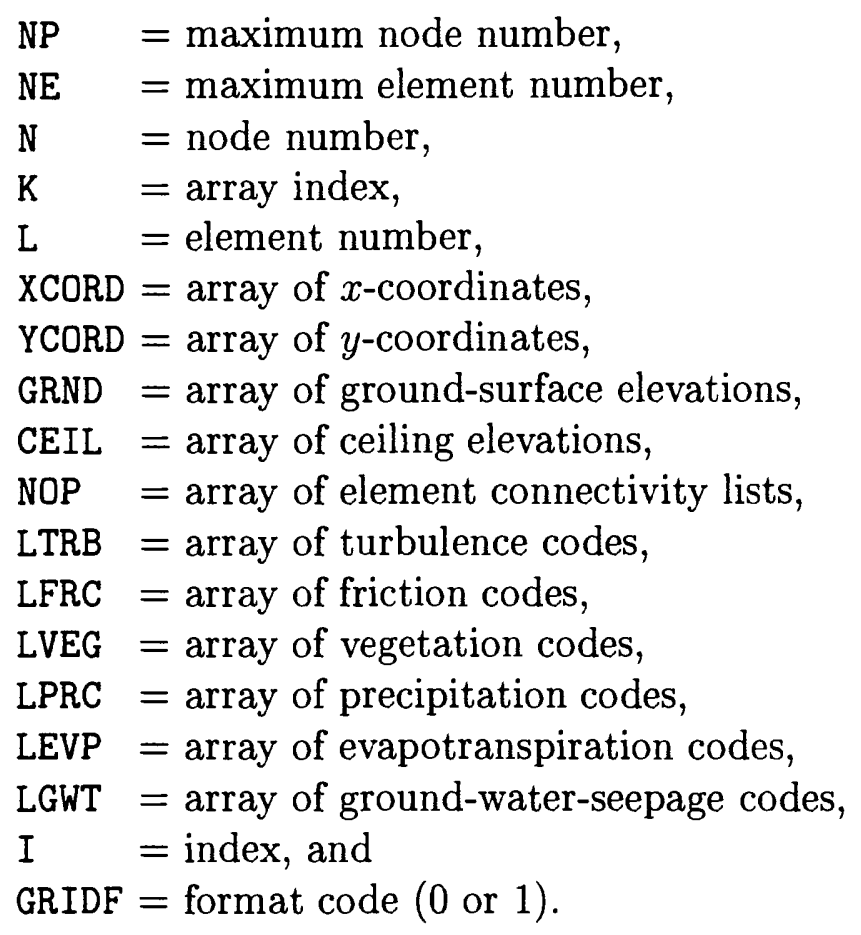

\section{Wind Data File}

A wind data file contains wind velocity and direction at node points. An unformatted wind data file can be read using the following FORTRAN statements:

READ (IUNIT) TIME, NODES

READ (IUNIT) (N, WINDV (N),WINDA (N), I=1, NODES)

A formatted wind data file can be read using the following FORTRAN statements:

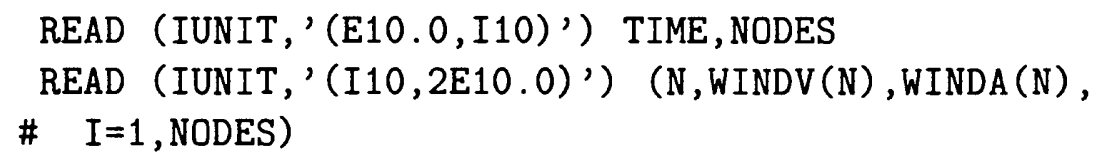

Variables contained in the preceding FORTRAN statements are defined below: 
IUNIT $=$ FORTRAN unit number of the wind data file, TIME = simulation time, in hours, NODES $=$ number of nodes for which wind data (that apply to the specified simulation time) are to be read,

$\mathrm{N}=$ node number,

WINDV = array of wind velocities, in feet per second (meters per second),

WINDA $=$ array of wind directions, in degrees measured counterclockwise from the positive $x$-direction (these are the directions toward which the wind is blowing), and

I $\quad=$ index.

\section{Ground-Water-Head Data File}

A ground-water-head data file contains the ground-water head at node points. An unformatted ground-water-head data file can be read using the following FORTRAN statements:

READ (IUNIT) TIME, NODES

READ (IUNIT) (N, HEAD (N), I=1, NODES)

A formatted ground-water-head data file can be read using the following FORTRAN statements:

READ (IUNIT, ' (E10.0,I10)') TIME, NODES

READ (IUNIT, '(I10, E10.0)') (N,HEAD (N), I=1, NODES)

Variables contained in the preceding FORTRAN statements are defined below:

IUNIT $=$ FORTRAN unit number of the ground-water-head data file, TIME = simulation time, in hours,

NODES $=$ number of nodes for which ground-water-head data (that apply to the specified simulation time) are to be read,

$\mathrm{N}=$ node number,

HEAD = array of ground-water heads, in feet (meters), and

I $\quad=$ index. 


\section{Initial-Condition Data File}

An initial-condition (flow) data file contains values of depth-averaged velocity in the $x$ - and $y$-directions, water depth, and the time derivative of these quantities at each node. These values are used as initial conditions for a simulation. An initial-condition data file is usually a flow data file that has been generated by a previous simulation. An unformatted initial-conditior data file can be read using the following FORTRAN statements:

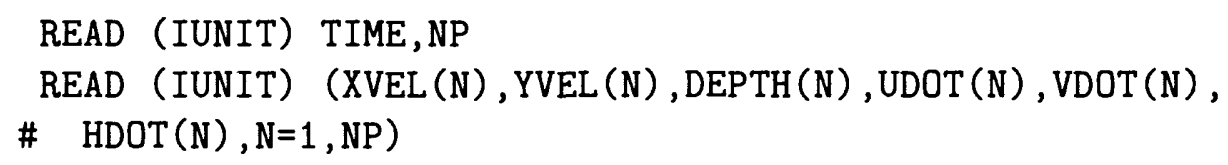

A formatted initial-condition data file can be read using the following FORTRAN statements:

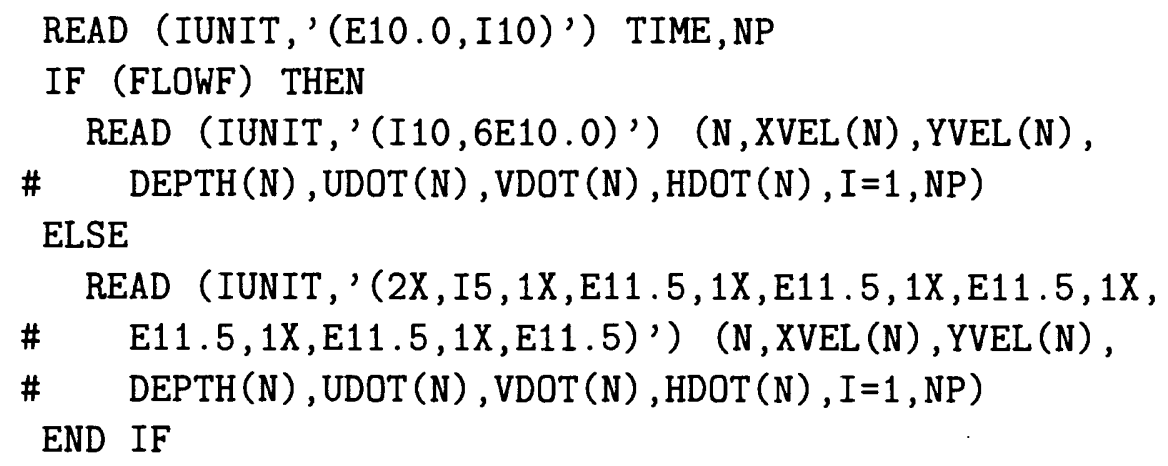

Variables contained in the preceding FORTRAN statements are defined below:

IUNIT = FORTRAN unit number of the initial-condition data file,

TIME = simulation time, in hours,

NP = maximum node number,

$\mathrm{N}=$ node number,

XVEL $=$ array of $x$-velocity components, in feet per second (meters per second),

YVEL = array of $y$-velocity components, in feet per second (meters per second),

DEPTH $=$ array of water depths, in feet (meters),

UDOT $=$ array of derivatives of $x$-velocity components with respect to 
time, in feet per second per second (meters per second per second),

VDOT $=$ array of derivatives of $y$-velocity components with respect to time, in feet per second per second (meters per second per second),

HDOT = array of derivatives of depth with respect to time, in feet per second (meters per second),

I $=$ index, and

FLOWF $=$ format code $(0$ or 1$)$.

\section{Boundary-Condition Data File}

A boundary-condition data file contains values of boundary-condition codes and boundary-condition specifications for nodes where boundary conditions are prescribed. During a time-dependent simulation, boundary-condition data for a node remain unchanged until new specifications are read. An unformatted boundary-condition data file can be read using the following FORTRAN statements:

READ (IUNIT) TIME, NODES

READ (IUNIT) (N, NFIX (N), XSPEC (N), YSPEC (N) , ZSPEC (N),

\# I=1, NODES)

A formatted boundary-condition data file can be read using the following FORTRAN statements:

READ (IUNIT, ' (E10.0,I10)') TIME, NODES

READ (IUNIT, ' (2I10, 3E10.0)') (N, NFIX (N), XSPEC (N),

\# $\quad \operatorname{SSPEC}(\mathrm{N}), \mathrm{ZSPEC}(\mathrm{N}), \mathrm{I}=1, \mathrm{NODES})$

Variables contained in the preceding FORTRAN statements are defined below:

IUNIT $=$ FORTRAN unit number of the boundary-condition data file, TIME = simulation time, in hours,

NODES $=$ number of nodes for which boundary-condition data (that apply to the specified simulation time) are to be read,

$\mathrm{N} \quad=$ node number,

NFIX = array of boundary-condition codes, 
XSPEC $=$ array of specified velocities, in feet per second (meters per second), or unit flows, in square feet per second (square meters per second), in the $x$-direction or tangent to the boundary, YSPEC $=$ array of specified velocities, in feet per second (meters per second), or unit flows, in square feet per second (square meters per second), in the $y$-direction or normal to the boundary; or total flows, in cubic feet per second (cubic meters per second), normal to the boundary,

ZSPEC $=$ array of specified water-surface elevations, in feet (meters), and I $\quad=$ index.

\section{Addendum to Section 9. Output Data Description-Depth-Averaged Flow Module: FLOMOD}

\section{Printed Output}

One-dimensional levee-seepage output is printed after the nodal solution values. For each levee segment, the levee-segment number, the node numbers and the water-surface elevations on each side of the levee, the flow through the levee segment, the flow under the levee segment, and the sum of the last two items are printed. Element inflows and outflows due to precipitation, evapotranspiration, and ground-water seepage are printed after weir, culvert, and levee-seepage output is printed.

\section{Output Data Files-Flow Data File}

Flow data written to the flow data file in text form is written in E12.5 format if FLOWF $=1$ or E10.3 format if FLOWF $=0$ (see the SWMS identification record). 


\section{REFERENCES}

Department of the Army, Office of the Chief of Engineers, 1978, Design and construction of levees: Washington, D. C., Department of the Army, Office of the Chief of Engineers, Engineer Manual 1110-2-1913.

Froehlich, D. C., 1989, Finite element surface-water modeling system: twcdimensional flow in a horizontal plane. Vol. I. Users manual: McLean, Va., U. S. Department of Transportation, Federal Highway Administrc,tion, Publication No. FHWA-RD-88-177, 286 p.

McDonald, M. G., and Harbaugh, A. W., 1988, A modular three-dimensional finite-difference ground-water flow model: U. S. Geological Survey Techniques of Water-Resources Investigations, book 6, chap. A1, 586 p.

Peter, Pavel, 1982, Canal and river levees: New York, Elsevier, 540 p.

Reid, R. O., and Whitaker, R. E., 1976, Wind-driven flow of water influenced by a canopy: Proceedings of the American Society of Civil Engineers, v. 102, no. WW1, p. 61-77. 